\title{
INSTRUMENTOS PARA UNA INTERVENCIÓN INSTITUCIONAL ESTRATEGICA EN LA FISCALIZACIÓN, SANCIÓN Y CUMPLIMIENTO AMBIENTAL: EL CASO DEL PROGRAMA DE CUMPLIMIENTO
}

\author{
TOOLS FOR A STRATEGIC INTERVENTION IN \\ ENVIRONMENTAL LAW ENFORCEMENT: THE CASE OF \\ ENVIRONMENTAL ENFORCEABLE UNDERTAKINGS
}

DOMINIQUE HERVÉ ESPEJO* MARIE CLAUDE PLUMER BODIN**

\section{RESUMEN}

La regulación contempla diversos instrumentos para que la Superintendencia del Medio Ambiente (SMA) ejerza sus potestades de fiscalización, sanción y cumplimiento. Destaca entre ellos el Programa de Cumplimiento (PDC) que ha sido el instrumento más utilizado en la práctica y cuyos criterios de aprobación han sido desarrollados por la SMA, según se explica en este trabajo. Se plantea la necesidad de aplicar el PDC y los demás instrumentos regulatorios disponibles con un enfoque responsivo estratégico, de manera de lograr por parte de la SMA una intervención eficaz y oportuna.

Palabras clave: Fiscalización, Sanción y Cumplimiento Ambiental, Programas de Cumplimiento.

\footnotetext{
* Profesora de Derecho Ambiental, Universidad Diego Portales. Abogada de la Universidad de Chile, Master en Derecho Ambiental del University College London (UCL) y Doctora en Derecho de la Pontificia Universidad Católica de Valparaiso. Ex-fiscal de la SMA. Correo electronico: dominique.herve@udp.cl ** Abogada de la Universidad de Chile, Magíster en Derecho Ambiental de la Universidad de Paris, Pantheon Sorbonne I-II. Ex-jefa de la División de Sanción y Cumplimiento de la SMA. Correo electrónico: mcplumer@gmail.com

Artículo recibido el 28 de diciembre de 2018 y aceptado para su publicación el 19 de mayo de 2019.
} 


\section{ABSTRACT}

The Environmental Enforcement Authority (SMA) has a range of diverse regulatory tools in order to exercise its control, sanction and compliance powers. Among them is the Environmental Enforceable Undertaking (PDC), which has been the most widely used instrument in practice and whose approval criteria have been developed by the SMA, as explained in this paper. There is a need to apply the PDC and the other available regulatory tools with a strategic responsive approach, in order to achieve an effective and timely intervention by the SMA.

\section{Keywords: Environmental Law Enforcement - Environmental Enforceable Undertakings.}

\section{INTRODUCCIÓN}

Existen en la actualidad diferentes percepciones respecto de la aplicación, por parte de la Superintendencia del Medio Ambiente (SMA), de los instrumentos regulatorios contenidos en su Ley Orgánica (LOSMA). Así, los regulados han considerado el enfoque utilizado, por lo general, como uno muy confrontacional o adversarial. ${ }^{1}$ Los ambientalistas, por el contrario, lo tienden a considerar muy cooperativo. ${ }^{2}$ Lo anterior no llama en principio la atención, dado los intereses diversos y muchas veces contrapuestos de los actores involucrados. Lo que sí debiera preocupar es -si la hubiera- la existencia de inconsistencias en el enfoque utilizado por la SMA para la aplicación de la batería de instrumentos que incorpora la LOSMA y que

\footnotetext{
1 En esta línea se puede mencionar, por ejemplo, la columna de opinión del abogado Sebastián Avilés, socio del estudio jurídico Moreno, Sáez y Avilés, donde cuestiona el enfoque utilizado por la SMA para determinar el cumplimiento por parte de los regulados del requisito reglamentario de "integridad", exigido para la aprobación de los Programas de Cumplimiento. Vid. Avilés, Sebastián, "Promoción del cumplimiento en materia ambiental", columna, Diario La Tercera, 22.11.2018, disponible en línea: https://www.latercera.com/pulso/noticia/promocion-del-cumplimiento-materiaambiental/412327/.

2 Por ejemplo, la objeción planteada por los interesados en el procedimiento sancionatorio seguido contra la empresa AES Gener S.A. (Alto Maipo) respecto del criterio adoptado por la SMA en cuanto a permitir diversas oportunidades a la empresa para modificar y complementar su programa de cumplimiento. Ver Superintendencia de Medio Ambiente (SMA), expediente sancionatorio Rol D-001-2017, “AES Gener S.A. (Alto Maipo)”, disponible en http://snifa.sma.gob.cl/v2/Sancionatorio/ Ficha/1498.
} 
permiten desarrollar una estrategia de intervención para la fiscalización, sanción y cumplimiento ambiental. Lo importante es, entonces, evaluar la institucionalización y coherencia del enfoque utilizado.

Desde la perspectiva del derecho comparado se ha desarrollado la teoría de la "regulación responsiva"3 que sostiene la existencia de una "pirámide de cumplimiento", según la cual el regulador cuenta con "una amplia diversidad de mecanismos de intervención, que se organizan jerárquicamente al modo de una pirámide que contiene en la cúspide sanciones drásticas, y en su base la sola persuasión". ${ }^{4}$ El sustento de este enfoque consiste en que el órgano regulador puede aplicar estos mecanismos respondiendo adecuadamente al grado de cooperación del regulado.

Este trabajo parte de la base que este enfoque teórico permitiría fundamentar una aplicación estratégica de los diversos instrumentos regulatorios contenidos en la LOSMA y la determinación de los criterios para establecer su procedencia. En efecto, es ya evidente que la sanción administrativa es sólo uno de los instrumentos que contempla la ley y, en la práctica, está lejos de ser el más utilizado. Así, se puede mencionar que del total de 779 procedimientos administrativos sancionatorios iniciados por la SMA, desde su entrada en vigencia en 2013 hasta diciembre de 2018, sólo 203 han terminado con una sanción. ${ }^{5}$ De los 576 restantes, 481 han sido objeto de la presentación de Programas de Cumplimiento (de los cuales 361 han sido aprobados). Por otra parte, la SMA ha optado también por utilizar otros mecanismos de intervención, tales como las "cartas de advertencia" o la "corrección temprana", en ciertos casos, así como las medidas provisionales -tanto en etapa pre como post sancionatoria-todos los cuales son instrumentos disponibles y distintos a la sanción administrativa y que permiten desarrollar una estrategia institucional que persigue lograr la eficacia del derecho ambiental.

El presente trabajo tiene por primer objetivo identificar y analizar, desde una perspectiva comparada, los diversos instrumentos regulatorios que entrega el legislador a la autoridad ambiental para elaborar una estrategia

\footnotetext{
3 Ayres, Ian; Braithwaite, John, Responsive Regulation. Transcending the Deregulation Debate, Oxford University Press, Oxford, 1992.

4 Soto, Pablo, "Sanciones administrativas como medidas de cumplimiento del Derecho: un enfoque funcional y responsivo aplicado al régimen sancionatorio ambiental", Ius et Praxis, 2016, Año 22, No2, p. 198.

5 Información obtenida del Sistema Nacional de Información de Fiscalización Ambiental (SNIFA) disponible en la página web de la SMA, en línea: http://snifa.sma.gob.cl/.
} 
de intervención y lograr el cumplimiento de la normativa ambiental (II). En segundo lugar, se pretende analizar en detalle los criterios que se han adoptado para determinar la procedencia de los Programas de Cumplimiento (PDC), entendiendo que este constituye el principal instrumento de nuestra legislación ambiental para lograr el cumplimiento (III). Finalmente, se procederá a identificar las debilidades y posibles mejoras del diseño regulatorio actual para realizar una intervención estratégica por parte de la SMA, considerando especialmente los PDC (IV). Se terminará con algunas conclusiones $(\mathrm{V})$.

\section{INSTRUMENTOS REGULATORIOS DISPONIBLES PARA LOGRAR EL CUMPLIMIENTO AMBIENTAL}

Existe un largo debate respecto a cuál es el mejor enfoque en materia de diseño regulatorio e institucional relacionado con las potestades de sanción y cumplimiento de la normativa ambiental. Las posibilidades van desde un enfoque basado en el "cumplimiento" - donde el regulador busca trabajar con el regulado en lograr un mejor estándar de cumplimiento y eficacia del derecho ambiental- hasta un enfoque fundamentalmente "punitivo", que persigue como fin principal, la disuasión en el regulado. ${ }^{6}$

Se puede sostener que el derecho comparado ha evolucionado hacia la creciente incorporación de nuevos mecanismos regulatorios que permiten a una autoridad adoptar una aproximación flexible entre estos dos enfoques frente al cumplimiento ambiental. ${ }^{7}$ Lo anterior se explica fundamentalmente a partir de razones de costo-eficacia. En efecto, la experiencia demuestra que la adopción de sanciones administrativas obedece, por regla general, a un proceso costoso en tiempo y recursos lo que exige contemplar la aplicación de otros instrumentos que permitan lograr de manera más eficiente los fines del cumplimiento ambiental. Pero también existen otras razones que justifican un enfoque más flexible y estratégico para el cumplimiento ambiental, tales como, la existencia de dificultades probatorias para la adopción de sanciones o la ausencia de una destinación de las sanciones aplicadas (multas) a un objetivo ambiental. Es así como resulta razonable que la sanción sea

\footnotetext{
6 Holder, Jane; Lee, Maria, Environmental Protection, Law \& Policy, Cambridge University Press, Cambridge, 2007, 2a Ed., pp. 381-416.

7 Macrory, Richard, Regulation, Enforcement and Governance in Environmental Law, Hart Publishing, Oxford \& Portland, Oregon, 2014, 2 Ed., pp. 21-108.
} 
aplicada sólo en aquellos casos en que realmente se justifique tal destinación de recursos y, en los demás casos, se pueda optar por otros mecanismos que también permitan a la autoridad cumplir sus objetivos.

A continuación revisaremos algunos ejemplos de derecho comparado que ilustran cómo las agencias sancionatorias de ciertos países han desarrollado estrategias flexibles en relación con la sanción y cumplimiento ambiental, identificando los principales mecanismos que han sido necesarios para lograrlo. Nos detendremos también a analizar el riesgo que lleva implícita una estrategia de este tipo. Luego, nos referiremos al caso chileno considerando tanto lo dispuesto en la LOSMA como la experiencia de la SMA hasta ahora.

1. Ejemplos de legislación comparada en el desarrollo de estrategias de fiscalización, sanción y cumplimiento ambiental

De acuerdo con GunNingham ${ }^{8}$ las agencias públicas que tienen a su cargo la sanción y cumplimiento ambiental utilizan mayormente estrategias híbridas de intervención, lo que les permite una aproximación flexible a la aplicación de los diversos instrumentos disponibles para lograr la eficacia del derecho ambiental. En su trabajo revisa diversos ejemplos de agencias regulatorias de Australia y Estados Unidos (tanto a nivel federal como estatal) Holanda e Inglaterra, identificando sus fortalezas y debilidades. En sus conclusiones destaca que para que una agencia defina su propia estrategia de intervención debe considerar el contexto en el que ésta se desenvuelve sin existir, por lo tanto, una especial combinación necesariamente más eficiente y eficaz que otra.

Dentro de la batería de instrumentos contemplados por las legislaciones comparadas para intervenir en materia de sanción y cumplimiento ambiental, se pueden mencionar al menos los siguientes:" "asistencia al cumplimiento" (compliance assistance, advice), "requerimientos de información" (information collection), "inspecciones" (inspections), "cartas de advertencia" (warnings, notices of violation), "notificaciones regulatorias" (statutory notices), "medidas, mandatos u órdenes" (formal administrative

\footnotetext{
8 GunNingham, Neil, “Enforcing Environmental Regulation”, Journal of Environmental Law, 2011, Vol. 23, N², pp. 172-175.

9 Estos ejemplos se han extraído de diversos trabajos académicos revisados para la elaboración de este artículo. Se identificarán las principales fuentes bibliográficas en la medida que se analice el instrumento específico.
} 
orders, enforcement orders, formal cautions, injunctions), "privilegios por revelación de información" (audit privileges, penalty amnesty programs), "compromisos ambientales ejecutables" (environmental enforceable undertakings), "multas o sanciones administrativas" (fixed or variable monetary administrative penalties), "revocación o suspensión de licencia" (licence revocation-suspension) acciones civiles (civil actions) y acciones criminales (criminal actions). A continuación abordaremos brevemente algunos de estos instrumentos.

En el extremo menos punitivo de este amplio espectro de instrumentos se pueden mencionar las "cartas de advertencia". Este mecanismo tiene por objeto poner en conocimiento del regulado que la agencia o autoridad administrativa tiene información de incumplimientos que le son imputables, con el objeto de incentivar que voluntariamente adopte medidas para resolver la situación y, también, explícita o implícitamente advertirle la posibilidad de la utilización de otros instrumentos en caso que no vuelva al cumplimiento. ${ }^{10}$ Las cartas de advertencia han sido ampliamente utilizadas por las autoridades administrativas para lograr el cumplimiento de la normativa en diversos sectores regulatorios, sin perjuicio que no existe mayor información disponible respecto a su eficacia. ${ }^{11}$ En efecto, este parece ser el mecanismo de intervención más utilizado por la Environmental Protection Agency (EPA) y las agencias ambientales estatales en EEUU al aplicar su estrategia sancionatoria. Lo mismo ocurre en otros países como Inglaterra, aún cuando se cuestiona su eficacia puesto que parece depender de la credibilidad que tenga la agencia en cuanto a su capacidad para imponer sanciones o medidas sancionatorias propiamente tales, en caso de persistir el incumplimiento. ${ }^{12}$

Las "notificaciones regulatorias" o statutory notices, por su parte, constituyen un mandato que emite la autoridad administrativa, respecto de un regulado, exigiéndole abstenerse de realizar determinadas conductas. Este mecanismo es mencionado dentro de los instrumentos existentes en Inglaterra y consiste en una orden administrativa en que se especifican los pasos que debe seguir el regulado para lograr el cumplimiento y los plazos

\footnotetext{
${ }^{10}$ ZINN, Matthew, "Policing Environmental Regulatory Enforcement: Cooperation, Capture and Citizen Suits", Stanford Environmental Law Journal, 2002, Vol. 21, pp. 87 y ss.

${ }^{11}$ WINDERS, Delcianna, "Administrative Law Enforcement, Warnings and Transparency", Ohio State Law Journal, 2018, Vol. 79:3, pp. 451 y ss.

${ }^{12}$ Ibid, pp. 468-469.
} 
para adoptarlos. ${ }^{13}$ Dependiendo de la regulación aplicable, la notificación puede incluir medidas de remediación relacionadas con el daño causado por el incumplimiento. MACRORY identifica diversas categorías dentro de las statutory notices. Por ejemplo: improvement notices (exigen mejoras en ciertas prácticas del regulado, dando espacios de tiempo para su cumplimiento), prohibition-suspension notices (prohíben una actividad hasta que se adopten acciones de remediación con el objeto de prevenir la ocurrencia de un daño), works notices (para prevenir o remediar la contaminación hídrica) $\mathrm{y}$ enforcement notices (se aplican en casos en que existan antecedentes de incumplimientos de una licencia o autorización, estableciendo los pasos y los plazos para rectificar, pudiendo también establecer medidas de remediación si la regulación lo permite y se ha causado un daño con el incumplimiento). ${ }^{14}$ El incumplimiento de estas notificaciones constituye por sí mismo una infracción y, por lo tanto, debe ser sancionado por la autoridad. Tal como en el caso de las cartas de advertencia, se señala la necesidad de dar seguimiento al cumplimiento de estas órdenes de manera de revestirlas de credibilidad. ${ }^{15}$

En el mismo sentido de las statutory notices recién explicadas, las formal administrative orders -identificadas en la literatura académica norteamericana- constituyen medidas de carácter administrativo que establecen la obligación de cumplir con ciertas medidas, por ejemplo, la obligación de adoptar ciertas tecnologías de tratamiento de efluentes, que se deben adoptar por el regulado para lograr llegar a un determinado estándar ambiental. ${ }^{16}$ Estas órdenes también pueden ser exigidas judicialmente (injunctions). ${ }^{17}$ Por otra parte, las penalty amnesty programs apuntan a incentivar la revelación voluntaria y la eliminación o reducción de los efectos de las infracciones, garantizando la abstención de la sanción por parte del regulador. ${ }^{18}$

Siguiendo la cadena de instrumentos disponibles por parte de las agencias a cargo de la sanción y cumplimiento ambiental, es relevante mencionar la incorporación del "compromiso ambiental ejecutable", como un instrumento novedoso que tiene su origen en los enforceable undertakings

\footnotetext{
${ }^{13}$ Macrory, cit. (n. 7), pp. 70-73.

${ }^{14}$ Idem.

15 Idem.

${ }^{16}$ ZINN, cit. (n. 10), p. 89.

${ }^{17}$ Idem.

${ }^{18}$ Idem.
} 
de Australia (creados en el contexto del derecho de competencia y consumo) y que se incorpora expresamente al derecho ambiental en el Reino Unido en el año $2010 .{ }^{19}$ Se trata de un acuerdo escrito entre el regulador y el infractor, en que este último propone ejecutar acciones específicas respecto a la materia relevante relacionada con el incumplimiento, como una alternativa a las sanciones administrativas o a una acción penal. ${ }^{20}$ Es decir, se trata de infracciones respecto de las cuales existe suficiente evidencia para llevar adelante un procedimiento sancionatorio, pero en vez de seguir el camino punitivo, el infractor se compromete a hacerse cargo de todos los aspectos relevantes relacionados con el incumplimiento. De esta manera, en la práctica se obtiene una modificación de la conducta empresarial a cambio de la abstención del proceso sancionatorio por parte de la autoridad. ${ }^{21}$ MACRORY propone, a su vez, una variante de este mecanismo que llama undertakings plus, el que permite combinar el compromiso de adoptar medidas por parte del regulado junto con la adopción de una sanción pecuniaria por parte de la autoridad. Esta alternativa puede ser conveniente en casos en que el regulado claramente haya obtenido una ganancia o beneficio económico a partir del incumplimiento. ${ }^{22}$

Según MACRORY, el instrumento permite también incorporar elementos restaurativos ${ }^{23}$ a la estrategia sancionatoria y puede facilitar las negociaciones entre el regulador, la empresa y, en los casos que corresponda, incluso las víctimas. En efecto, sostiene que los compromisos ejecutables pueden llegar a incluir medidas de compensación, reembolso y reparación. ${ }^{24} \mathrm{~A}$ su vez, sostiene que las medidas comprometidas deben ser proporcionales a la infracción y relacionarse claramente con ella, debiendo quedar establecido el plazo en el que se llevarán a cabo. El instrumento, por último, debe ser público y su seguimiento debe ser riguroso. ${ }^{25}$

\footnotetext{
${ }_{19}$ Pedersen, Ole, "Environmental Enforcement Undertakings and Possible Implications: Responsive, Smarter or Rent Seeking?”, The Modern Law Review 2013, Vol. 76, №2, pp. 319 y ss.

${ }^{20}$ Ibid, p. 319.

${ }^{21}$ MACrory, cit. (n. 7), p. 49.

${ }^{22} \mathrm{Ibid}$, p. 78. Cabe señalar que esta variante no fue incorporada finalmente en la legislación que reguló los compromisos ejecutables, esta es, la Regulatory Enforcement and Sanctions Act 2008.

${ }^{23}$ La justicia restaurativa adopta un enfoque distinto a la justicia retributiva, puesto que el énfasis está en el futuro, en lo que se debe restaurar, entender y fortalecer con el objetivo de que el daño no vuelva a ocurrir. MACRORY, cit. (n.7), p. 81.

${ }^{24}$ Ibid, p. 77.

${ }^{25}$ Idem.
} 
Siguiendo estas recomendaciones, la Environmental Civil Sanctions (England) Order 2010, que implementa en materia ambiental la legislación sobre sanción y cumplimiento de 2008, establece cuatro criterios que se deben cumplir para aceptar un compromiso ambiental ejecutable. ${ }^{26}$ Estos son los siguientes: que las medidas deben asegurar que no se continúe con la infracción; que en la medida de lo posible se restaure la situación ambiental a la que existía con anterioridad a la infracción; que las medidas deben ir en beneficio de las personas afectadas por la infracción; y, cuando la restauración del daño causado no es posible, la medida debe asegurar un beneficio equivalente o un mejoramiento del medio ambiente. Sin embargo, en un interesante análisis sobre la aplicación práctica del instrumento en el Reino Unido, Pedersen cuestiona que la autoridad ambiental inglesa haya aceptado una gran cantidad de donaciones para organizaciones ambientales, como parte de las medidas incorporadas en los compromisos ambientales ejecutables aprobados. ${ }^{27}$ En particular, se trata de medidas relacionadas con infracciones respecto del manejo de residuos, las que no generan un daño identificable ni víctimas específicas. En efecto, según el autor, esta práctica puede generar incentivos perversos, cuestionamientos respecto de quién debe recibir las donaciones, problemas relacionados con el destino de las donaciones, entre otros..$^{28}$ Lo anterior, permite entender la dificultad que enfrenta un regulador respecto de los criterios a adoptar para aprobar este tipo de instrumentos.

Finalmente, cabe destacar que MACrORY sostiene que la aplicación y procedencia de los compromisos ejecutables debe quedar claramente establecida en la política sancionatoria de una agencia y que este instrumento no debe ser considerado como un derecho del regulado, sino que su aprobación debe quedar siempre sujeta a la discrecionalidad de la autoridad. ${ }^{29}$

Continuando con el análisis de los diversos instrumentos disponibles para una estrategia de sanción y cumplimiento ambiental -y acercándose hacia el extremo más disuasivo- se pueden mencionar las "sanciones administrativas o multas", las que según MACRORY, constituyen una alternativa efectiva e intermedia entre los instrumentos más persuasivos y

\footnotetext{
${ }^{26}$ Pedersen, cit. (n. 19), pp. 324-326.

${ }^{27}$ Ibid, pp. 331-341.

${ }^{28}$ Idem.

${ }^{29}$ Macrory, cit. (n. 7), p. 77.
} 
la sanción criminal. ${ }^{30} \mathrm{El}$ autor recomienda un sistema en que la autoridad cuente con la posibilidad de adoptar multas fijas o variables, considerando esta última opción como una buena alternativa respecto de infracciones más serias, de manera que permitan al regulador una respuesta apropiada a las circunstancias específicas del caso. ${ }^{31}$ En efecto, considera que las multas fijas debieran consistir en un monto más bien bajo y aplicarse respecto de infracciones menores o respecto de grandes volúmenes de infracciones. La legislación debe en estos casos definir la naturaleza de la infracción y el monto de la multa y la autoridad administrativa debe mantener su discrecionalidad sobre la decisión de aplicar en el caso concreto la multa fija u otro instrumento.

Por último, las "acciones criminales" deben también ser parte del sistema sancionatorio ambiental respecto de aquellos casos en que se identifiquen infracciones graves, continuas, repetidas, intencionales y que impliquen consecuencias muy serias para el medio ambiente o las personas. MACRORY también propone, para estos casos, salidas alternativas tales como las siguientes: profit orders (exigen el pago de las utilidades o beneficios económicos provenientes de la infracción, además de la multa que se pueda imponer), corporate rehabilitation orders (exigen al regulado adoptar ciertas acciones durante un periodo de tiempo determinado, en orden a reformar las prácticas organizacionales, además o en vez de la multa que se pueda imponer) y publicity orders (implica publicitar la sanción). ${ }^{32}$

A partir de toda la experiencia comparada se puede concluir que una aproximación flexible por parte de las agencias públicas competentes frente a la sanción y cumplimiento ambiental parece ser la decisión correcta. Sin embargo, no se debe pasar por alto que este tipo de estrategias puede implicar el surgimiento de cuestionamientos al ejercicio de la discrecionalidad administrativa en la definición de los instrumentos aplicables en cada situación. Es decir, la adopción de una estrategia flexible por parte de la autoridad puede llegar a ser interpretada, en ciertos casos, como mera incapacidad, ineficiencia o ausencia de recursos o derechamente como una "captura" de la misma por parte del regulado.

Frente a este problema, las soluciones planteadas por la doctrina y la experiencia comparada apuntan a que el regulador debe explicitar los

\footnotetext{
${ }^{30}$ Ibid, p. 53.

${ }^{31}$ Ibid, pp. 54-67.

${ }^{32}$ Ibid, p. 107.
} 
criterios que utilizará en la determinación de su estrategia, ya sea a través de la publicación de sus políticas y lineamientos estratégicos como a través del ejercicio de sus potestades de manera transparente. A su vez, el principio de proporcionalidad y la consistencia en su actuación constituyen límites al ejercicio de la discrecionalidad administrativa. Por último, una adecuada participación pública y los correspondientes mecanismos de impugnación, permiten a la ciudadanía cumplir un rol relevante en la solución de este problema.

\section{El diseño regulatorio contemplado en la LOSMA para el desarrollo de una estrategia de fiscalización, sanción y cumplimiento ambiental}

Es en este contexto comparado en el que pretendemos insertar el análisis de lo dispuesto por la LOSMA en relación con la fiscalización, sanción y cumplimiento ambiental. Sin perjuicio que la reforma legislativa de 2010 introduce un nuevo enfoque en la materia -donde se enfatiza el uso de otras herramientas que van más allá de la adopción de sanciones administrativas para lograr el cumplimiento- ${ }^{33}$ la legislación ambiental nacional no fue lo suficientemente clara en la adhesión a un enfoque flexible y estratégico en el ejercicio de la potestad sancionadora. Como se verá a continuación, los instrumentos regulatorios contenidos en la LOSMA para incentivar el cumplimiento son fundamentalmente dos -la autodenuncia y los PDC- sin embargo, sus límites y particularidades han exigido que se utilicen y adopten otros mecanismos de incentivo, que no se contemplaron expresamente como tales, pero que en la práctica agregan flexibilidad al actuar de la SMA. Se puede sostener que esta forma de intervención flexible y que apunta hacia la elaboración de una estrategia en materia de fiscalización, sanción y cumplimiento ambiental, se ha trabajado de manera gradual e incremental por la SMA lo que ha permitido ir estableciendo paulatinamente criterios consistentes en esta materia tanto para los regulados como para la sociedad civil.

A continuación, se identifican los instrumentos que contempla la legislación ambiental y que se han utilizado por la SMA en el ejercicio de sus potestades de fiscalización, sanción y cumplimiento. Estos son: la asistencia al regulado (artículo 3, letra u), la autodenuncia (artículo 41), el programa de cumplimiento (artículo 42) y el plan de reparación ambiental

${ }^{33}$ Ossandón, Jorge, Incentivos al Cumplimiento Ambiental, Libromar, Santiago, 2015, p. 2. 
(artículo 43). Se puede agregar también la denuncia ciudadana (artículo 21). Junto con estos instrumentos se han ido incorporando, en la práctica, otros que permiten a la SMA transitar hacia el desarrollo de una estrategia de incentivo al cumplimiento, tales como, la programación y subprogramación de la fiscalización (artículos 16-20), los requerimientos de información (artículo 3, letra e), las medidas provisionales y las urgentes y transitorias (artículo 48 y artículo 3 letras g y h), y las llamadas "cartas de advertencia" y la oportunidad de "corrección temprana" frente a la existencia de hallazgos menores por parte de la SMA. ${ }^{34}$

Se analizarán brevemente estos mecanismos con el objeto de exponer la batería completa de instrumentos que utiliza actualmente la autoridad ambiental para intervenir en el ejercicio de sus potestades de fiscalización y sanción, para luego, en la siguiente sección detenernos en particular en el Programa de Cumplimiento, que en la práctica se ha transformado en el principal mecanismo de incentivo al cumplimiento con que cuenta la SMA.

La "asistencia al regulado" se encuentra dentro de las funciones y atribuciones que reconoce la ley a la SMA, en los siguientes términos: "proporcionar asistencia a sus regulados para la presentación de planes de cumplimiento o de reparación, así como para orientarlos en la comprensión de las obligaciones que emanan de los instrumentos individualizados en el artículo $2^{\circ}$ de esta ley". ${ }^{35} \mathrm{El}$ alcance de esta atribución, en la práctica, ha sido determinado a través de la resolución que define la organización interna de la SMA. En efecto, la Resolución Exenta Nº424 de 12 de mayo de 2017 detalla, dentro de las funciones de cada unidad administrativa, el ámbito en que le corresponde aplicar esta función. Así, la Fiscalía y la División de Fiscalización ejercen esta función en las materias que competan a su división. ${ }^{36}$ La División de Sanción y Cumplimiento, por su parte, la ejerce específicamente respecto de los requisitos y criterios para la presentación y aprobación de los PDC, autodenuncias y los planes de reparación, así como otras materias que competan a su división. Especial relevancia tiene también esta función respecto de las oficinas regionales de la SMA, que la ejercen en lo que dice relación con las actividades de fiscalización ambiental que estén

\footnotetext{
${ }^{34}$ Estos últimos dos mecanismos han sido desarrollados en la práctica por la SMA y no tienen un fundamento legal expreso.

${ }^{35}$ Artículo 3, letra u), LOSMA.

${ }^{36}$ Por ejemplo: cumplimiento de medidas provisionales pre-procedimentales, presentación de denuncias ciudadanas, cumplimiento de obligaciones de seguimiento ambiental, desarrollo de actividades de fiscalización, por nombrar algunas.
} 
radicadas en la respectiva región. Mediante esta atribución la SMA puede orientar y promover el cumplimiento de las obligaciones ambientales, en una etapa previa a la adopción de procedimientos administrativos formales. ${ }^{37}$

En cuanto a la "autodenuncia", se trata de un instrumento que se incorpora en la legislación ambiental chilena mediante el artículo 41 de la LOSMA, y que permite a la autoridad eximir del monto de la multa al infractor que denuncie estar cometiendo, por sí, una infracción a la normativa de su competencia, siempre y cuando ejecute íntegramente el programa de cumplimiento establecido en el artículo 42. En caso que el infractor ya hubiese concurrido a autodenunciarse con anterioridad, la utilización por segunda y tercera vez de dicho mecanismo otorga una rebaja de hasta un $75 \%$ y $50 \%$ respectivamente de la multa impuesta por la SMA en el proceso sancionatorio correspondiente, siempre y cuando ejecute íntegramente el programa de cumplimiento. Para que proceda la exención o rebaja se deben cumplir los siguientes requisitos: el infractor debe suministrar información precisa, verídica y comprobable, respecto de los hechos que constituyen la infracción; $y$, debe poner fin de inmediato a los mismos, adoptando todas las medidas necesarias para reducir o eliminar los efectos negativos. ${ }^{38}$ Este mecanismo no ha tenido una gran aplicación en la práctica, en parte por su complicado diseño regulatorio que impide considerarlo un real incentivo para los regulados, al no existir ventajas comparativas en relación con la presentación de un PDC..$^{39}$

El "plan de reparación", por su parte, permite al infractor -en caso de que haya sido sancionado por la SMA y habiéndose acreditado en el procedimiento sancionatorio la existencia de daño ambiental- presentar voluntariamente una propuesta de plan de reparación del daño, que de ser aprobado y mientras se ejecute, suspende el plazo de prescripción para

\footnotetext{
${ }^{37}$ Especial relevancia presenta esta función para las oficinas regionales de la SMA, en lo que dice relación con la gestión de la fiscalización a la norma de emisión de ruidos (Decreto Supremo №38 de 2011 del Ministerio de Medio Ambiente).

${ }^{38}$ Estos criterios han sido explicados por la SMA a través de su Guía para la presentación de autodenuncias por infracciones a instrumentos de carácter ambiental, de septiembre de 2018. Vid. Superintendencia de Medio Ambiente (eds.), Guía para la presentación de autodenuncias por infracciones a instrumentos de carácter ambiental, Gobierno de Chile - SMA, Santiago, 2018, 22 pp., disponible en línea: https://portal.sma.gob.cl/index.php/portal-regulados/instructivos-y-guias/ autodenuncias/.

${ }^{39}$ Hasta diciembre de 2018 se han presentado 28 autodenuncias en total, de las cuales 19 han sido admitidas, 7 rechazadas y 2 se encuentran en análisis (información obtenida directamente de la División de Sanción y Cumplimiento, SMA).
} 
ejercer la acción por daño ambiental ante los tribunales ambientales. Si el plan se ejecuta satisfactoriamente, la acción se extingue. Hasta la fecha no ha existido ningún caso que permita analizar su aplicación en la práctica.

La "denuncia ciudadana" consiste en el mecanismo con que cuenta cualquier persona para poner en conocimiento de la SMA el incumplimiento de instrumentos de gestión ambiental. ${ }^{40}$ En el evento que producto de tales denuncias se inicie un procedimiento administrativo sancionador, el denunciante tendrá la calidad de interesado en el precitado procedimiento, sin tener que acreditar un interés en el mismo. La SMA deberá analizar la seriedad y mérito de la denuncia y, en caso que no exista, dispondrá el archivo de la misma. Con el objeto de instruir acerca de la gestión interna de las denuncias ciudadanas, la Resolución Exenta No 839 de 12 de septiembre de 2016, incorpora algunos criterios que permiten dar mayor eficiencia, eficacia y oportunidad a la fiscalización y sanción que derive de este mecanismo. Es así como se incorporan dos criterios de optimización y relevancia para la gestión de denuncias, que determinan la urgencia en la realización de actividades de fiscalización. Estos criterios son "el nivel de gravedad de los hechos denunciados" (corresponde al grado de afectación a la salud de las personas y/o al medio ambiente, constatado o potencialmente generado con motivo o causa directa de los hechos denunciados) y la "conmoción pública" (corresponde al contexto social asociado con la denuncia y con los efectos de los hechos descritos en la comunidad). Luego se detallan algunos ejemplos en que se entiende que dichos criterios se manifiestan, tales como casos de afectación grave o riesgo significativo sobre la salud de la población, de presunción de daño a componentes del medio ambiente y denuncias con alta conmoción pública. Considerando estos criterios, la autoridad puede definir una estrategia de intervención a partir de la denuncia ciudadana.

Junto con estos mecanismos, la SMA puede también utilizar una serie de otros instrumentos para desarrollar una estrategia de intervención en materia de fiscalización, sanción y cumplimiento ambiental. Así, la "programación y subprogramación" de la fiscalización ambiental permite planificar y priorizar la fiscalización de ciertos instrumentos de gestión ambiental, por sectores económicos y en relación con determinadas

\footnotetext{
${ }^{40}$ Hasta ahora se han presentado un promedio de 1.500 denuncias ciudadanas anuales a la SMA. De estas, alrededor de un $50 \%$ corresponden a denuncias por incumplimiento a la norma de emisión de ruidos. Datos obtenidos de la Noticia: "SMA presenta su Cuenta Pública 2017”, 28 de marzo de 2017, disponible en la página web del SMA, en línea: https://portal.sma.gob.cl/index.php/2018/04/25/ sma-presenta-su-cuenta-publica-2017v2/ (visitada al 22.12.2018).
} 
regiones del territorio nacional. La Resolución Exenta No 1171 de 11 de diciembre de 2015 dicta instrucciones para la elaboración de los programas y subprogramas de fiscalización ambiental, determinando los criterios que integran el modelo de fiscalización estratégica a aplicar anualmente. Este modelo considera "factores de vulnerabilidad ambiental del territorio, de percepción social de los proyectos o unidades fiscalizables y de los niveles de peligrosidad de las operaciones desarrolladas, a fin de generar una aproximación del riesgo ambiental que representan los distintos proyectos o unidades fiscalizables en una zona geográfica". De esta manera, anualmente la SMA prioriza y planifica sus actividades de fiscalización y la de los organismos subprogramados, en lo que dice relación con los instrumentos de gestión ambiental de su competencia.

Cabe también mencionar el "requerimiento de información" a los regulados, como un instrumento con el que cuenta la SMA para el ejercicio de sus potestades de fiscalización y sanción. Este mecanismo constituye una herramienta que se utiliza ampliamente para obtener antecedentes por parte de los regulados, agregando información relevante a la obtenida por la SMA a través de sus propias actividades de fiscalización. También son muy relevantes las "medidas provisionales" y las "medidas urgentes y transitorias" (MUT), que permiten a la SMA intervenir en situaciones de riesgo ambiental, exigiendo a los regulados adoptar ciertas conductas correctivas que permitan evitar la continuación del riesgo y prevenir la ocurrencia de futuros daños.

Por último, las llamadas "cartas de advertencia" se han aplicado principalmente para la gestión de denuncias ciudadanas, de informes de fiscalización y de seguimiento ambiental presentados por titulares, cuando existen antecedentes sobre posibles infracciones menores a instrumentos de gestión ambiental de competencia de la SMA, en particular normas de emisión de ruidos, normas de emisión de residuos líquidos industriales o medidas de planes de descontaminación. Por su parte, la "corrección temprana" de incumplimientos menores ha sido utilizada por la SMA en casos de fiscalizaciones que arrojan antecedentes que dan cuenta de una o más eventuales disconformidades con la normativa ambiental. Tal como señala la SMA en sus "Bases Metodológicas para la Determinación de Sanciones Ambientales", si la unidad fiscalizable "acredita ante la SMA, mediante medios comprobables, que ellas han sido subsanadas, se darán por corregidas, lo que quedará señalado en el correspondiente memorándum de devolución de informe de fiscalización, el que se publicará en el SNIFA, 
conjuntamente con dicho informe". ${ }^{41}$

Es así como la SMA dispone de una diversidad de instrumentos que, utilizados de manera estratégica, le permitirían desarrollar una política flexible ante el incumplimiento ambiental. En la práctica, sin embargo, estos instrumentos se han utilizado todavía sin un enfoque integral, es decir, sin una organización responsiva de los mismos de acuerdo con el comportamiento de cada regulado. Sin perjuicio de lo anterior, tal como se ha explicado, la SMA ha ido desarrollando respecto de cada instrumento una perspectiva estratégica, faltando, principalmente, un proceso de integración y sinergia entre todos ellos en pos de una respuesta más eficaz por parte de la autoridad.

Es en este contexto que la SMA ha ido desarrollando y adoptando criterios respecto de la aprobación y ejecución de los PDC, algunos de los cuales ya han sido confirmados por los tribunales. A eso se refiere la siguiente sección.

\section{EL PDC COMO PRINCIPAL INSTRUMENTO REGULATORIO DE LA LOSMA PARA EL CUMPLIMIENTO AMBIENTAL}

La LOSMA es innovadora al incorporar el PDC, por cuanto no hay un instrumento equivalente en otros ámbitos regulatorios nacionales, siendo quizás, el más cercano, el "Programa de promoción al cumplimiento ambiental", regulado en la Ley de Acuerdos de Producción Limpia. ${ }^{42}$ Sin embargo, aún cuando el legislador tuvo una intención clara al reconocer el PDC y los otros instrumentos de incentivo ya mencionados, en ninguna parte la LOSMA incorporó expresamente el término de "mecanismos de incentivo al cumplimiento". Dicha denominación se encuentra únicamente a nivel reglamentario, en el Título II del Decreto Supremo 30, de 2012, del Ministerio del Medio Ambiente, ${ }^{43}$ que se refiere a los "Instrumentos de Incentivo al Cumplimiento", dentro del cual se encuentra el PDC.

\footnotetext{
${ }^{41}$ Superintendencia de Medio Ambiente (eds.), Bases metodológicas para la determinación de sanciones ambientales. Actualización, aprobada por Res. Exenta No 85, de 22 de enero de 2018, Gobierno de Chile - SMA, Santiago, 2017 (pero 2018), p. 42 (especialmente nota $\mathrm{N}^{0}$ 57).

${ }^{42}$ El artículo $8^{\circ}$ de la Ley de Acuerdos de Producción Limpia, contenida en el Artículo Décimo de la Ley N ${ }^{\circ}$ 20.416, de 2010, que Fija Normas Especiales para las Empresas de Menor Tamaño, incorpora los "programas de promoción del cumplimiento de la normativa".

${ }^{43}$ Decreto Supremo No 30 de 2012, del Ministerio del Medio Ambiente, Reglamento sobre Programas de Cumplimiento, Autodenuncia y Planes de Reparación (D. Of. 11.02.2013).
} 
Ahora bien, resulta de interés relevar que la LOSMA considera al PDC como un instrumento aplicable dentro del procedimiento sancionatorio ${ }^{44}-\mathrm{a}$ diferencia de los otros instrumentos de incentivo ${ }^{45}$, , aspecto que si bien constituye un elemento relevante que potencia su fuerza como instrumento de incentivo al cumplimiento, adolece de algunas debilidades en su regulación, las que se abordarán más adelante. ${ }^{46}$ Ahora nos detendremos en analizar sus características y los criterios que se han ido adoptando para su aprobación.

Sin duda, el PDC constituye el mecanismo de incentivo al cumplimiento ambiental de mayor aplicación. ${ }^{47}$ Las razones que podrían justificar lo anterior podrían resumirse en dos aspectos: uno de "carácter regulatorio", esto es, la LOSMA diseñó de manera correcta el beneficio para los interesados directos; ${ }^{48}$ y otro de "carácter práctico-discrecional", referido a que ante la baja densidad normativa de su regulación, la SMA -hasta la fecha- ha ejercido su discrecionalidad de manera consistente y fundada, otorgando ámbitos de flexibilidad al instrumento, pero con claros límites, sustentados en los requisitos de aprobación del PDC.

Tal como se indicó, el PDC debe ser presentado una vez incoado el procedimiento sancionatorio, disponiendo el infractor de diez días para hacerlo, plazo que puede ser ampliado de conformidad lo dispone el artículo 26 de la Ley $\mathrm{N}^{\circ} 19.880$, de 2003, disponiendo en definitiva -mediando dicha ampliación- de quince días hábiles. Dicho plazo deja de manifiesto que es una quimera sostener que un PDC en su primera presentación cumplirá

\footnotetext{
${ }^{44}$ De conformidad lo dispone el artículo 42, iniciado un procedimiento sancionatorio, el infractor podrá presentar un PDC en el plazo de 10 días, contados desde el acto que lo incoa.

${ }^{45}$ De conformidad a lo dispuesto en el artículo 41 de la LOSMA, la Autodenuncia debe ser presentada antes de cualquier inicio de investigación por parte de la SMA respecto de los hechos sobre las cuales se presenta la autodenuncia. Según las Bases Metodológicas para la Determinación de Sanciones de la SMA, se entiende como "inicio de la etapa de investigación", aquella en que la SMA ha realizado una de las siguientes actuaciones, en relación a los hechos imputados: solicitud de información a un organismo del Estado, fiscalización realizada, solicitud de medidas provisionales, requerimiento de información al presunto infractor $\mathrm{u}$ otros sujetos regulados o cualquier otra actividad de investigación dirigida al esclarecimiento de los hechos. Por su parte el Plan de Reparación, puede presentarse, una vez terminado el procedimiento sancionatorio, de conformidad lo dispone el artículo 43 de la LOSMA.

${ }^{46}$ Véase la sección IV de este trabajo.

${ }^{47}$ Plumer, Marie Claude; EspinozA, Ariel; Murh, Benjamín, "El Programa de Cumplimiento: Desarrollo actual e importancia del instrumento para la solución de conflictos ambientales", Revista de Derecho Ambiental, 2018, año VI, Nº9 (Ene-Jun), pp. 209-236.

${ }^{48}$ Son interesados directos, el infractor (beneficiado con la no sanción) y la SMA (que representa el interés público). Además lo son los "interesados" declarados de conformidad al artículo 21 de la LOSMA y, aquellos que, acreditando su interés ambiental en el procedimiento administrativo, hayan sido declarados como tales en el mismo.
} 
con los requisitos para su aprobación. De allí que, acertadamente, la SMA haya establecido como práctica administrativa la de observar el PDC, ${ }^{49} \sin$ perjuicio de su atribución para rechazarlo de plano, cuando este no cumple con los requisitos de aprobación del artículo 9 del DS N³0, de 2012.

A continuación se analizarán aspectos relacionados con el diseño regulatorio del PDC, su baja densidad normativa y la práctica de la SMA en la aplicación de los criterios de aprobación del instrumento.

\section{El diseño regulatorio}

El PDC es de manera efectiva un mecanismo alternativo a la sanción administrativa, ${ }^{50}$ ya que una vez ejecutado satisfactoriamente, se dará por concluido el procedimiento sancionatorio, sin sanción, constituyendo una forma anormal o extraordinaria de poner término al mismo. ${ }^{51}$ Así lo establece el inciso $6^{\circ}$ del artículo 42 de la LOSMA, que señala "Cumplido el programa dentro de los plazos establecidos y de acuerdo a las metas fijadas en él, el procedimiento administrativo se dará por concluido". Es así como es posible sostener que el legislador acepta despojarse, desasirse de su potestad sancionadora, si y solo si, el PDC aprobado se ejecuta satisfactoriamente.

El incentivo comprendido en el PDC puede ser representado mediante una balanza, en el que se conjugan, por una parte, el interés público del cumplimiento ambiental obtenido en un tiempo determinado y, por la otra, el interés privado obtenido por el infractor al eximirse de la sanción,

\footnotetext{
49 Práctica que ha sido reconocida por el Segundo Tribunal Ambiental, 29 de septiembre de 2017, "Sociedad Contractual Minera Corporación de Desarrollo del Norte contra la Superintendencia del Medio Ambiente", causa Rol "R"- 82-2015, disponible en www.tribunalambiental.cl, considerando cuadragésimo cuarto: "Que, en virtud de lo informado y de las normas analizadas, el Tribunal considera que, pese a que las observaciones y correcciones de oficio realizados por la SMA sean una práctica habitual- observada en cerca del $80 \%$ de los casos informados, según lo expuesto en el considerando anterior- la entidad fiscalizadora no tiene una obligación legal de realizar dichas observaciones o correcciones, encontrándose plenamente facultada para rechazar de plano un programa de cumplimiento, en caso que éste no cumpla con los criterios de aprobación prescritos en el artículo $9^{\circ}$ del D.S. $N^{\circ} 30$, de $2012 \ldots .$.

${ }^{50}$ Cuestión que no es similar en los otros mecanismos de incentivo. En efecto, la Autodenuncia -salvo que sea la primera y que se apruebe y ejecute el PDC respectivo- concluirá generalmente con la imposición de una sanción. Así lo indica el artículo 41 inciso segundo de la LOSMA. Por su parte, los planes de reparación constituyen un mecanismo de incentivo indirecto, dado que proceden solo una vez dictada la sanción y, siempre que ella se refiera a infracciones clasificadas con daño ambiental, siendo el incentivo, en caso de aprobación y ejecución del referido plan de reparación, la extinción de la acción por daño ambiental, según lo dispone el artículo 43 de la LOSMA.

${ }^{51}$ OsSANDÓn, cit. (n. 33), p. 203.
} 
generando para este último, no solo un beneficio económico directo, sino sobre todo reputacional.

El equilibrio de dicha balanza, sin embargo, es frágil. Efectivamente, como se verá en el punto siguiente, la baja densidad normativa de su regulación, otorga importantes márgenes de discrecionalidad a la autoridad, los que, mal aplicados, pueden generar ya sea la desnaturalización del instrumento o derechamente su desincentivo.

De lo anterior se deduce que la consolidación del PDC como un instrumento de incentivo al cumplimiento ambiental, no solo depende del correcto diseño regulatorio, sino también de decisiones motivadas, consistentes, y que aseguren su finalidad, esto es, el interés público comprometido en él.

\section{La baja densidad normativa y el mayor margen de discrecionalidad administrativa}

La LOSMA regula el PDC en un solo artículo, el ya mencionado artículo 42,52 complementado con lo dispuesto en el Título II del D.S. $\mathrm{N}^{\circ} 30$, de 2012. Es en ese reducido marco regulatorio que debe la autoridad resolver innumerables aspectos asociados a los PDC, dejando un amplio

\footnotetext{
${ }^{52}$ Artículo 42, de la LOSMA indica que: "Iniciado un procedimiento sancionatorio, el infractor podrá presentar en el plazo de 10 días, contado desde el acto que lo incoa, un programa de cumplimiento. Para estos efectos se entenderá como programa de cumplimiento, el plan de acciones y metas presentado por el infractor, para que dentro de un plazo fijado por la Superintendencia, los responsables cumplan satisfactoriamente con la normativa ambiental que se indique.

No podrán presentar programas de cumplimiento aquellos infractores que se hubiesen acogido a programas de gradualidad en el cumplimiento de la normativa ambiental o hubiesen sido objeto con anterioridad de la aplicación de una sanción por parte de la Superintendencia por infracciones gravísimas o hubiesen presentado, con anterioridad, un programa de cumplimiento, salvo que se hubiese tratado de infracciones leves. Con tal objeto, deberá considerarse el plazo de prescripción de las infracciones señaladas en el artículo 37.

Aprobado un programa de cumplimiento por la Superintendencia, el procedimiento sancionatorio se suspenderá.

Dicho procedimiento se reiniciará en caso de incumplirse las obligaciones contraídas en el programa, evento en el cual se podrá aplicar hasta el doble de la multa que corresponda a la infracción original dentro del rango señalado en la letra b) del artículo 38, salvo que hubiese mediado autodenuncia.

Cumplido el programa dentro de los plazos establecidos y de acuerdo a las metas fijadas en él, el procedimiento administrativo se dará por concluido.

El Reglamento establecerá los criterios a los cuales deberá atenerse la Superintendencia para aprobar un programa de cumplimiento.

Con todo, la presentación del programa de cumplimiento y su duración interrumpirán el plazo señalado en el artículo 37".
} 
margen de discrecionalidad para su aplicación. El control jurisdiccional de las decisiones de la SMA, realizado por los Tribunales Ambientales y la Corte Suprema, contribuyen a la fijación de límites y criterios referidos a los PDC. ${ }^{53}$ Sin embargo, las definiciones jurisprudenciales todavía son pocas y también existen muchas materias que aún no han sido discutidas en tribunales. $^{54}$

La referida discrecionalidad permite aceptar grados de flexibilidad en el PDC, pero asimismo, obliga a velar y garantizar que no se vulnere su naturaleza y finalidad. Así, el ejercicio de dicha discrecionalidad está sometida al control de ciertos elementos que deben concurrir, no pudiendo exigir requisitos arbitrarios, desviarse de su finalidad, o imponer criterios que no están expresamente regulados en la normativa. ${ }^{55}$

El artículo 9, del DS $\mathrm{N}^{\circ} 30$, de 2012, limita la discrecionalidad, en

\footnotetext{
${ }^{53}$ Algunas sentencias de los Tribunales Ambientales y de la Corte Suprema que se han pronunciado sobre PDC son: Primer Tribunal Ambiental, 6 de junio de 2018, "Interchile S.A. con Superintendencia del Medio Ambiente", Rol "R"-4-2018; Segundo Tribunal Ambiental, 22 de julio 2016, "Sociedad Vinícola Miguel Torres S.A. con Superintendencia del Medio Ambiente", Rol "R"-68-2015; Segundo Tribunal Ambiental, 2 de febrero de 2017, "Ecomaule S.A. con Superintendencia del Medio Ambiente", Rol "R"-112-2016; Segundo Tribunal Ambiental, 24 de febrero de 2017, "Pastene Solis con Superintendente del Medio Ambiente", Rol "R"-104-2016; Segundo Tribunal Ambiental, 28 de junio de 2017, "Carrasco Martínez con Superintendencia del Medio Ambiente", Rol "R"-116-2016; Segundo Tribunal Ambiental, 29 de septiembre de 2017, "Sociedad Contractual Minera Corporación de Desarrollo del Norte con Superintendencia del Medio Ambiente", cit. (n. 49); Segundo Tribunal Ambiental, 20 de octubre de 2017, "Leon Cabrera con Superintendencia del Medio Ambiente", Rol "R"-132-2016; Segundo Tribunal Ambiental, 30 de diciembre de 2017, "Compañía Minera Nevada SpA con Superintendencia del Medio Ambiente", Rol "R"-75-2015; Segundo Tribunal Ambiental, 29 de junio de 2018, "López Aránguiz con Superintendencia del Medio Ambiente", Rol "R"-163-2017; Segundo Tribunal Ambiental, 21 de agosto de 2018, "Sociedad Química y Minera de Chile S.A. con Superintendencia del Medio Ambiente", Rol "R"-160-2017; Segundo Tribunal Ambiental, 14 de septiembre de 2018, "Velozo Rencoret y Otros con Superintendente del Medio Ambiente", Rol "R"-153-2017; Tercer Tribunal Ambiental, 19 de agosto de 2016, "Barria Oyarzo con Superintendencia del Medio Ambiente", Rol "R"-36-2016; Tercer Tribunal Ambiental, 28 de noviembre de 2016, "Corporación Puelo Patagonia con Superintendencia del Medio Ambiente", Rol "R"-28-2016; Tercer Tribunal Ambiental, 2 de febrero de 2018, "Stipicic Escauriaza con Superintendencia del Medio Ambiente", Rol "R"-58-2017. Corte Suprema, 3 de julio de 2017, Rol N67.418-2016; Corte Suprema, 17 de julio de 2017, Rol N 58.986-2016; Corte Suprema, 6 de noviembre de 2017, Rol N³6.202-2017; Corte Suprema, 5 de marzo de 2018, Rol N¹1.485-2017; Corte Suprema, 22 de mayo de 2018, Rol N8456-2017; Corte Suprema, 29 de agosto de 2018, Rol $\mathrm{N}^{\circ}$ 3572-2018; Corte Suprema, 30 de octubre de 2018, Rol 16.328-2018.

${ }^{54}$ Dentro de los temas que todavía no son abordados por sentencias judiciales cabe mencionar, por ejemplo, el alcance de los impedimentos para presentar un PDC establecidos en el inciso tercero del artículo 42; la incompatibilidad de un PDC respecto a infracciones clasificadas con daño ambiental; el plazo máximo de ejecución de un PDC; el alcance de la finalidad del PDC de "asegurar el cumplimiento de la normativa ambiental infringida”, en relación a la naturaleza de las infracciones, es decir ¿existen infracciones que por razones de hecho no pueden ser objeto de un PDC?

${ }^{55}$ Segundo Tribunal Ambiental, 2 de febrero de 2017, cit. (n. 53).
} 
cuanto impone criterios que deben cumplirse para la aprobación de un PDC, los que se analizarán a continuación. Cabe señalar además que toda norma que otorga márgenes de discrecionalidad, supone la imposición del deber de motivar y justificar suficientemente la decisión. Asimismo -y como se ha mencionado en la primera parte de este trabajo- la dictación de Guías, Políticas o Instructivos por parte de la autoridad son esenciales para limitar dicha discrecionalidad.

En ese sentido, gradualmente la SMA ha ido estableciendo sus criterios a través de estos mecanismos, un ejemplo de ello es la "Guía para la presentación de Programas de Cumplimiento por infracciones a instrumentos de carácter ambiental" de junio de $2018 .^{56}$ En dicha Guía la SMA fija el alcance de los criterios de aprobación de un $\mathrm{PDC}^{57}$ fundándose para ello ya sea en las sentencias de los Tribunales Ambientales y de la Corte Suprema, como asimismo, en su propia práctica administrativa.

\section{Los criterios de aprobación de un PDC}

El artículo 42 regula el PDC en cuanto a su definición, la oportunidad procesal para presentarse, los efectos en el caso de su aprobación y ejecución satisfactoria y las restricciones o impedimentos para ser presentados. Es decir, el artículo 42 establece una regulación gruesa y de carácter genérica. Por su parte, el Título II, del DS N³0, de 2012, precisa y establece los requisitos para la aprobación y ejecución satisfactoria del instrumento.

De la definición de PDC contenida en el inciso segundo del artículo 42, es posible identificar los elementos centrales y constitutivos del mismo, a saber, i) su contenido, esto es, el plan de acciones y metas; ii) la existencia de un sujeto, quien debe presentarlo; iii) un plazo, dentro del cual debe ejecutar el plan de acciones y metas; y, iv) la finalidad del mismo. Complementa el artículo 42, el artículo 7 del DS 30, de 2012, que regula el contenido mínimo de los PDC, este es: a) descripción de los hechos, actos

\footnotetext{
56 Superintendencia de Medio Ambiente (eds.), Guía para la presentación de Programas de Cumplimiento por infracciones a instrumentos de carácter ambiental, Gobierno de Chile - SMA, Santiago, 2018, 56 pp., disponible en línea: https://portal.sma.gob.cl/index.php/download/guia-parala-presentacion-de-programas-de-cumplimiento-2/?wpdmdl=14300\&masterkey=5be3278b9af81.

${ }^{57}$ Criterio de los impedimentos para presentar un PDC (punto 1.3); criterio de integridad referido a presentar acciones y metas respecto de cada infracción de la formulación de cargos (punto 3.1.1); criterio respecto a los aspectos relativos a los efectos generados por la infracción (punto 2.1), entre otros.
} 
u omisiones que constituyen la infracción en que se ha incurrido, así como sus efectos; b) Plan de acciones y metas que se implementarán para cumplir satisfactoriamente con la normativa ambiental que se indique, incluyendo las medidas adoptadas para reducir o eliminar los efectos negativos generados por el incumplimiento; c) Plan de seguimiento, que incluirá un cronograma de las acciones y metas, indicadores de cumplimiento; y d) Información técnica y de costos estimados relativa al programa de cumplimiento, que permita acreditar su eficacia y seriedad.

Es sobre los referidos elementos constitutivos, en que reposan, como se verá más adelante, los criterios de aprobación de un PDC. Se procederá primero a analizar los elementos que contempla la regulación, para posteriormente detenerse en los criterios de aprobación establecidos en el reglamento y desarrollados por la SMA.

En relación al "contenido del PDC" es relevante señalar que, al incluir el instrumento un plan de acciones y metas, denota una característica del mismo, cual es la necesaria gradualidad en llegar al cumplimiento normativo. Sostener lo contrario llevaría el instrumento a un absurdo, en tanto el cumplimiento inmediato es una posibilidad mínima de ocurrencia. ${ }^{58}$ Ahora bien, la gradualidad indicada, no debe permitir decisiones que signifiquen formas de eludir la responsabilidad o de aprovecharse de la infracción, por lo que cobran nuevamente relevancia los límites a la discrecionalidad administrativa, aplicando correctamente el artículo 9 del DS 30, 2012. ${ }^{59}$

Respecto al "sujeto" que presenta el PDC-calificado como "infractor"60 por la LOSMA - cabe señalar que ni la referida ley ni el DS N³0 de 2012 lo definen. Para efectos del PDC, el alcance que debe darse al "sujeto-infractor"

\footnotetext{
${ }^{58}$ En aquellos casos excepcionales en que las acciones se encuentran ejecutadas antes de la aprobación del PDC, la SMA ha aplicado un criterio que podría denominarse de la "adicionalidad", esto es, ir un poco más allá del cumplimiento normativo infringido. Así por ejemplo, los siguientes expediente sancionatorios: Superintendencia de Medio Ambiente (SMA), expediente sancionatorio Rol D-0132017, "Hidronor Chile S.A.- Pudahuel", disponible en: http://snifa.sma.gob.cl/v2/Sancionatorio/ Ficha/1517; Superintendencia de Medio Ambiente (SMA), expediente sancionatorio Rol F-049-2016, "Relleno Cerro La Leona", disponible en: http://snifa.sma.gob.cl/v2/Sancionatorio/Ficha/1481; Superintendencia de Medio Ambiente (SMA), expediente sancionatorio Rol D-064-2016, "Minera Los Pelambres", disponible en: http://snifa.sma.gob.cl/v2/Sancionatorio/Ficha/1438. Es relevante indicar que la Corte Suprema, 22 de mayo de 2018, Rol N 8456-2017, ha resuelto que una obligación contenida en el PDC prevalece aun cuando esta sea más exigente que la obligación contenida en la norma infringida, de lo contrario indica, se omitiría la satisfacción de objetivos reparatorios que el titular del proyecto se ha auto impuesto.

${ }^{59}$ Artículo 42 de la LOSMA, en relación al artículo 7 y 12, del D.S. N³0, de 2012, cit. (n. 43).

${ }^{60}$ Artículo 42 inciso segundo y tercero de la LOSMA, en relación al artículo 2 letra g) y artículo 6 , ambos del DS N³0 de 2012.
} 
es relevante, pues determina, la imposibilidad de presentar un PDC -salvo que se trate de infracciones leves, en cuyo caso procederá siempre ${ }^{61}-$ en el caso que este haya obtenido previamente la aprobación de un PDC en otro procedimiento sancionatorio iniciado por infracciones graves, dentro de los tres años contados desde la aprobación del mismo. ${ }^{62} \mathrm{Al}$ respecto, la SMA ha ido asentando el alcance del concepto "sujeto-infractor". Así, por ejemplo, en los casos Rol D-024-2014, Aquaprotein, y Rol D-081-2018, Relleno Sanitario Los Ángeles, los infractores disponían con anterioridad de un PDC aprobado, por lo que con la nueva formulación de cargos (FDC) -que comprendía al menos una infracción clasificada de grave- se les aplicó el impedimento o restricción de entrada, establecido en el inciso tercero del artículo 42.63 Ahora bien, el concepto de "sujeto-infractor" también ha sido analizado en el caso que existan instalaciones relacionadas, aun cuando correspondan a distintas unidades fiscalizables. ${ }^{64}$ Para efectos de la potestad sancionadora, la SMA ha relevado la relación funcional y de dependencia para determinar si aplica o no algún impedimento indicado en el artículo 42 de la LOSMA. Aún cuando este criterio no se ha recogido expresamente para los PDC, sí se ha aplicado respecto de la determinación de la sanción según el artículo 40 de la LOSMA. En el caso Rol D-33-2016, Embalse Carén, para efectos de la aplicación de la circunstancia contenida en la letra e) del artículo 40, esto es, conducta anterior del infractor, se consideró la relación de dependencia entre el Embalse Carén y la Mina División El Teniente. En suma, si se aplicara este criterio para efectos de un PDC, Tranque Carén y Mina El Teniente constituirían una misma unidad de proyecto, es decir, una misma unidad fiscalizable.

En cuanto al "plazo", se refiere al tiempo dentro del cual debe cumplirse el PDC. La determinación del plazo de ejecución del PDC es una atribución de la SMA. ${ }^{65}$ De conformidad lo indica el inciso segundo del artículo 42

\footnotetext{
${ }^{61}$ Dicha interpretación ha sido aplicada por la SMA y se encuentra consolidada como práctica administrativa, pero no ha sido ratificada por los Tribunales Ambientales o la Corte Suprema.

${ }^{62}$ En relación con los impedimentos, v. Plumer, Espinoza y Murh, cit. (n. 47).

${ }^{63}$ Dicho criterio se encuentra reconocido y aplicado a nivel de práctica administrativa de la SMA, Guía para la Presentación de Programas de Cumplimiento... cit. (n. 56), punto 1.3, p. 6.

${ }^{64}$ La Resolución Exenta SMA, № 1184 de 2015 (14.12.2015) define Unidad Fiscalizable como "Unidad física en la que se desarrollan obras, acciones o procesos, relacionados entre sí y que se encuentran regulados por uno o más instrumentos de carácter ambiental de competencia de la Superintendencia”. ${ }^{65}$ En SMA, Guías para la presentación de Programas de Cumplimiento... cit. (n. 56), se establece el plazo promedio de duración de un PDC, a saber: “...es levemente mayor a los 8 meses y, en términos generales, lo esperable es que un PDC no supere los 2 años y medio, en total”.
} 
de la LOSMA, el plazo resulta ser un criterio relevante al ponderar la seriedad y responsabilidad del infractor y se encuentra comprendido, como se indicará más adelante, en el criterio negativo referido a no aprobar PDC manifiestamente dilatorios.

Por último, respecto a la "finalidad", el objetivo del PDC es revertir, en un plazo acotado, los incumplimientos contenidos en la formulación de cargos, asegurando el cumplimiento de la normativa ambiental incumplida, haciéndose cargo de los efectos causados. Por lo tanto, su objetivo último, sin dudas, es la protección del medio ambiente.

Indicados los elementos constitutivos de un PDC, a continuación se analizarán los criterios de aprobación de los PDC, regulados por el artículo 9 del DS N 30 de 2012. ${ }^{66}$ Dichos criterios pueden clasificarse en criterios positivos y criterios negativos.

\subsection{Los criterios positivos para aprobar un PDC}

Estos corresponden a los criterios de integridad, eficacia y verificabilidad.

i) El "criterio de integridad" consiste en que "las acciones y metas deben hacerse cargo de todas y cada una de las infracciones en que se ha incurrido y sus efectos". ${ }^{67}$ De lo anterior se desprende que comprende una doble dimensión, aquella referida a que el PDC debe comprender todos los cargos contenidos en la FDC y, aquella que comprende cada cargo en particular. En esta última dimensión, se entiende que debe considerar tanto las acciones y metas para asumir el hecho infraccional como sus efectos. Ambas dimensiones, han sido confirmadas por los Tribunales Ambientales. Es así como para efectos de la integridad y su relación con la FDC, se ha señalado que el programa de cumplimiento debe incorporar todas las

${ }^{66}$ D.S. N 30, 2012, cit. (n. 43). Su artículo 9 dispone: “Criterios de Aprobación. La Superintendencia para aprobar un programa de cumplimiento deberá atenerse a los siguientes criterios: a) Integridad: Las acciones y metas deben hacerse cargo de todas y cada una de las infracciones en que se ha incurrido y de sus efectos. b) Eficacia. Las acciones y metas del programa deben asegurar el cumplimiento de la normativa infringida, así como contener y reducir o eliminar los efectos de los hechos que constituyen la infracción. c) Verificabilidad. Las acciones y metas del programa de cumplimiento deben contemplar mecanismos que permitan acreditar su cumplimiento.

En ningún caso se aprobarán programas de cumplimiento por medio de los cuales el infractor intente eludir su responsabilidad, aprovecharse de su infracción, o bien, que sean manifiestamente dilatorios".

${ }^{67}$ Artículo 9, letra a), LOSMA. 
infracciones contenidas en la formulación de cargos $\mathrm{y}$, sobre las cuales es posible presentar un programa de cumplimiento. ${ }^{68}$ Dicho alcance, ha indicado el Tribunal Ambiental, no es contrario al fin u objetivo del PDC, instrumento que está establecido para la protección del medio ambiente y cuya finalidad es corregir el incumplimiento normativo y los efectos de éste en una oportunidad distinta, previa, a la culminación del término del procedimiento sancionatorio. ${ }^{69}$

Por tanto, no constituye una facultad de la Superintendencia ni del regulado determinar qué cargos se incorporan a un PDC. No existe un derecho a "elegir" por cuáles cargos de la FDC se presenta el PDC. En efecto, ello implicaría derechamente la desnaturalización de la finalidad del instrumento, desviándolo a priorizar el interés privado, por sobre el interés público comprometido en el mismo. Efectivamente, el PDC no se estructura sobre la base de una situación de igualdad entre el regulado y la SMA, que permita negociar su contenido y alcance..$^{70}$ Lo anterior, pues el PDC tiene como objetivo último la protección del medio ambiente y su presentación y aprobación impone al administrado el cumplimiento de una serie de requisitos regulados en el artículo 42 de la LOSMA, como asimismo impone a la SMA, ajustarse a la Ley y su reglamento en el ejercicio de su facultad de decidir su aprobación o rechazo, de acuerdo a lo dispuesto en el artículo $3^{\circ}$ letra r) de la LOSMA.

Por otra parte, la integridad de cada cargo en particular implica considerar el hecho infraccional propiamente tal y sus efectos. ${ }^{71}$ Existe, en suma, un binomio "infracción-efectos", indisoluble, que se expresa en

\footnotetext{
${ }^{68}$ En este sentido, debe precisarse que la SMA ha consolidado el criterio referido a los impedimentos del artículo 42 de la LOSMA, especialmente el referido a que si un cargo en la FDC ha sido clasificado por daño ambiental, irreparable o reparable, de conformidad al artículo 36 letras a) o b), de la LOSMA, no procede presentar un PDC en razón a que la LOSMA previó otros instrumentos con la finalidad de, la reparación del daño ambiental, para lo cual reguló por un lado, en sede administrativa el Plan de Reparación (artículo 43), o el ejercicio de acción de daño ambiental en sede jurisdiccional (artículos 51 y siguientes, de la Ley $\mathrm{N}^{\circ} 19.300$, modificada por la Ley $\mathrm{N}^{\circ} 20.417$ ). Por otro lado, cabe reiterar que de acuerdo con la práctica de la SMA un PDC puede presentarse siempre cuando se trate de infracciones leves.

${ }^{69}$ Segundo Tribunal Ambiental, 30 de diciembre de 2016, cit. (n. 53), considerandos del trigésimo al trigésimo sexto; y Segundo Tribunal Ambiental, 29 de septiembre de 2017, cit. (n. 49), considerando cuadragésimo noveno.

${ }^{70}$ Segundo Tribunal Ambiental, 2 de febrero de 2017, cit. (n. 53), considerando cuadragésimo segundo.

${ }^{71}$ Segundo Tribunal Ambiental, 22 de julio de 2016, cit. (n. 53); Segundo Tribunal Ambiental, 28 de junio de 2017, cit. (n. 53); Segundo Tribunal Ambiental, 24 de febrero de 2017, cit. (n. 53); Segundo Tribunal Ambiental, 14 de septiembre de 2018, cit. (n. 53); entre otros; Tercer Tribunal Ambiental, 19 de agosto de 2016, cit. (n. 53).
} 
la necesidad que el PDC considere acciones para abordar la infracción propiamente tal y acciones para hacerse cargo de los efectos que esta haya generado, si correspondiere, o su descarte.

Por tanto, podría indicarse que el criterio de integridad es más bien un criterio formal, de carácter cuantitativo, que se expresa en determinar si el PDC presentado cumple o no con presentar acciones y metas respecto de todas y cada una de las infracciones de la FDC, como asimismo de sus efectos, sin ser relevante la calidad o efectividad de dichas acciones, lo que debe analizarse en el criterio de eficacia.

ii) El "criterio de eficacia", según lo dispone la letra b) del artículo 9 del D.S N 30 de 2012, implica que un PDC es eficaz cuando las acciones y metas del programa aseguran el cumplimiento de la normativa ambiental infringida, así como elimina, contiene y reduce los efectos de los hechos que constituyen la infracción. Así el infractor no sólo tiene una obligación de volver al cumplimiento ambiental, sino que, conjuntamente con ello, debe hacerse cargo de los efectos de las infracciones cometidas, ya sea conteniéndolos, reduciéndolos o eliminándolos. ${ }^{72}$

La eficacia es, sin lugar a dudas, el criterio de mayor complejidad, dado los múltiples tipos infraccionales posibles. Efectivamente, en este criterio también debe considerarse el binomio "infracción-efecto", en el sentido que el PDC debe hacerse cargo de ambos. En todo caso, en materia de efectos, parece otorgarse un margen mayor de discrecionalidad a la autoridad, en cuanto no exige que producido un efecto a propósito de la infracción, en el marco del PDC éste deba ser necesariamente eliminado, ya que podría aceptarse la contención y reducción como un mínimo. Lo anterior, se deduce simplemente del tenor literal del artículo 9 del DS N³0 de 2012, que indica "... así como contener y reducir o eliminar los efectos de los hechos que constituyen la infracción". Es decir, no se trataría de requisitos copulativos. Cuestión distinta es lo que se refiere al hecho infraccional, ya que pareciera que allí no hay margen mayor. Efectivamente, el PDC debe asegurar el cumplimiento de la normativa ambiental infringida. La clave en esta parte está en qué se debiera entender por "asegurar el cumplimiento de la normativa infringida". La complejidad surge, por ejemplo, ante infracciones

\footnotetext{
${ }^{72}$ Segundo Tribunal Ambiental, 22 de julio de 2016, cit. (n. 53); Segundo Tribunal Ambiental, 24 de febrero de 2017, cit. (n. 53); Segundo Tribunal Ambiental, 20 de octubre de 2017, cit. (n. 53); Segundo Tribunal Ambiental, 28 de junio de 2017, cit. (n. 53).
} 
que impliquen no realizar mediciones en un período determinado; o no haber realizado la captura y rescate de fauna previo a la construcción; o no haber realizado el monitoreo arqueológico previo a la excavación o instalación de equipamiento. Este tipo de infracciones implicaría que desde un punto de vista fáctico o temporal, no habría acción posible que permitiera asegurar el cumplimiento de la normativa ambiental infringida en el marco del PDC, dado que es imposible en estos casos "volver al cumplimiento". ${ }^{73}$ Otra situación similar se da en casos en que dentro del plazo promedio de un PDC, no es posible obtener la meta del cumplimiento de la obligación, sino que sólo acciones preparatorias para lograrlo, pues su cumplimiento pleno excede el plazo razonable que puede contemplar el PDC..$^{74}$

Lo anterior llevaría a preguntarse si hay infracciones, que por sus circunstancias propias, hacen inviable que un PDC cumpla el criterio de eficacia. La respuesta a ello aún no está totalmente resuelta, los Tribunales Ambientales no se han enfrentado a este tipo de discusiones, quedando solamente la práctica administrativa de la SMA. Un ejemplo de esta práctica administrativa es la aceptación, en ciertos casos - bajo un criterio que podría denominarse de "continuidad operacional"-, de acciones que solo son posibles de adoptar en razón a que la obligación permanece en el tiempo, así entonces, con la adopción de dichas acciones, se evitarían futuros incumplimientos. ${ }^{75}$

El criterio de eficacia es medular, por cuanto es en el que reposa, junto

\footnotetext{
${ }^{73}$ En algunos casos, se ha debido rechazar PDC asociados al componente arqueológico por esta razón. Por ejemplo: Superintendencia de Medio Ambiente (SMA), expediente sancionatorio Rol D-043-2017, "Empresa de Transportes METRO S.A.", disponible en: http://snifa.sma.gob.cl/v2/Sancionatorio/ Ficha/1569; Superintendencia de Medio Ambiente (SMA), expediente sancionatorio Rol D-067-2017, "Fuerte Corral 2", disponible en: http://snifa.sma.gob.cl/v2/Sancionatorio/Ficha/1608.

${ }^{74}$ Un ejemplo de ello son las infracciones asociadas al componente forestal. V. los expedientes sancionatorios SMA, Rol D-064-2016, "Minera Los Pelambres”, cit. (n. 58); y SMA, Rol F-049-2016, "Relleno Cerro La Leona", cit. (n. 58).

${ }^{75}$ Representativo de aquello son los PDC aprobados por infracciones al D.S. N 90 , del 2000, del Ministerio Secretaría General de la Presidencia, que establece norma de emisión para la regulación de contaminantes asociados a las descargas de residuos líquidos a aguas marinas y continentales superficiales. En estos casos, la obligación de realizar mediciones en ciertos periodos de tiempo es permanente. Algunos ejemplos, entre muchos: Superintendencia de Medio Ambiente (SMA), expediente sancionatorio Rol F-059-2015, "Viña Morandé - Malloa", disponible en: http://snifa. sma.gob.cl/v2/Sancionatorio/Ficha/1331; Superintendencia de Medio Ambiente (SMA), expediente sancionatorio Rol F-029-2016, "Carozzi Planta Teno", disponible en http://snifa.sma.gob.cl/v2/ Sancionatorio/Ficha/1421; Superintendencia de Medio Ambiente (SMA), expediente sancionatorio Rol F-048-2017, "Riles Viña Echeverría", disponible en: http://snifa.sma.gob.cl/v2/Sancionatorio/ Ficha/1630.
} 
con los criterios negativos, la seriedad y efectividad de un PDC.

iii) El "criterio de verificabilidad", de acuerdo a la letra c) del artículo 9 del D.S N³0 de 2012, consiste en que las acciones y metas del programa de cumplimiento deben contemplar mecanismos que permitan acreditar su cumplimiento.

En resumen, de los tres criterios indicados, al presentar un PDC, el sujeto pasivo del procedimiento sancionatorio debe hacerse cargo de todas y cada una de las infracciones por las que se han formulado cargos y de los cuales es dable presentar un $\mathrm{PDC}^{76}$ y de sus efectos (integridad); debe asegurar el retorno al cumplimiento de la normativa infringida (eficacia) y, contemplar mecanismos de acreditación de dicho cumplimiento (verificabilidad).

\subsection{Los criterios negativos para aprobar un PDC}

El inciso final del artículo 9 indica que "En ningún caso se aprobarán programas de cumplimiento por medio de los cuales el infractor intente eludir su responsabilidad, aprovecharse de su infracción, o bien, que sean manifiestamente dilatorios". Constituyen entonces verdaderas prohibiciones de carácter general, destinadas a impedir o evitar la aprobación de PDC defectuosos ${ }^{77}$ o derechamente ilegales.

La SMA, en la "Guía para la Presentación de PDC", indica al respecto que la aplicación de estos criterios "...se ha ejercido en la forma de un principio de orientación para determinar el tiempo y la forma que debe contemplar un PDC para ser aprobado, considerando su finalidad preventiva y protectora del medio ambiente..." ${ }^{78}$ Ejemplo de la aplicación de estos criterios son los casos de infracciones por elusión al SEIA en que se propone, en el marco del PDC, continuar con la actividad mientras ésta se evalúa ambientalmente. ${ }^{79}$

\footnotetext{
${ }^{76}$ V. los impedimentos del artículo 42 de la LOSMA.

77 Segundo Tribunal Ambiental, 14 de septiembre de 2018, cit. (n. 53), considerando octogésimo sexto.

${ }^{78}$ V. SMA, Guías para la presentación de Programas de Cumplimiento... cit. (n. 56), Punto 3.1.1.

79 Por ejemplo, el rechazo de los PDC presentados en: Superintendencia de Medio Ambiente (SMA), expediente sancionatorio Rol D-029-2018, "Levaduras Collico", disponible en: http://snifa.sma.gob.cl/v2/ Sancionatorio/Ficha/1702; Superintendencia de Medio Ambiente (SMA), expediente sancionatorio Rol D-046-2017, "Alifrut San Fernando", disponible en http://snifa.sma.gob.cl/v2/Sancionatorio/Ficha/1576; Superintendencia de Medio Ambiente (SMA), expediente sancionatorio Rol D-070-2017, "Viña Urcelay", disponible en http://snifa.sma.gob.cl/v2/Sancionatorio/Ficha/1615.
} 
Vulnerar estos criterios o prohibiciones puede implicar una suerte de "autorización" a infringir. Lo señala claramente en un voto de minoría el Ministro de la Corte Suprema, Sergio Muñoz, en la causa Rol Nº88.9482016, en la que se resolvió: " $3{ }^{\circ}$ Que, sin embargo, la proposición de un plan de cumplimiento no libera, no autoriza y no permite que las infracciones se sigan cometiendo; ello, por una parte, atentaría contra la finalidad preventiva y protectora del medio ambiente antes reseñada y, por otra, configuraría una forma de co-autoría de futuras infracciones entre el titular del proyecto y la autoridad. En efecto, prueba de ello es que la Administración goza de facultades que incluso permiten, en el intertanto, la paralización del proyecto infractor, de lo que se sigue que el plan de cumplimiento nunca puede importar una especie de permiso para seguir perpetuando transgresiones a la normativa ambiental".

En ese mismo sentido se pronuncia el Primer Tribunal Ambiental en causa Rol No R-4-2018, al indicar en su considerando trigésimo tercero que “... Aceptar una acción de este tipo, en una etapa esencialmente provisoria de un proyecto como lo es la fase de construcción, conllevaría avalar que la persistencia de una infracción que genera efectos negativos, se puede eximir de sanción alguna, lo que se desvía totalmente de los fines para los que fue concebida la herramienta del PDC, que es justamente volver al cumplimiento de la normativa ambiental, y contener, minimizar y reducir, los efectos negativos derivados de una determinada infracción".

Los criterios negativos, junto al criterio de eficacia, son centrales para garantizar que el PDC no se desvíe de su finalidad, esto es, del interés público que debe siempre priorizar.

IV. DEBILIDADES DEL ACTUAL DISEÑO REGULATORIO Y POSIBILIDADES DE MEJORA PARA UNA ESTRATEGIA DE INTERVENCION INSTITUCIONAL

Tal como se ha indicado en las secciones previas, la LOSMA ya contempla una batería de instrumentos que permitirían a la SMA adoptar una intervención flexible y estratégica respecto del cumplimiento ambiental. Sin perjuicio de ello, también ha quedado en evidencia la existencia de algunas debilidades del diseño regulatorio en esta materia. A continuación se busca identificar dichas debilidades y proponer algunas ideas para su fortalecimiento y mejora.

En particular respecto del PDC, cabe señalar que su reducida regulación, 
tanto a nivel legal como reglamentario, debilita el instrumento en cuanto a su finalidad de protección ambiental. En efecto, parece necesario que esta regulación indique sus aspectos centrales, como por ejemplo, explicitar legalmente que la finalidad del instrumento es precisamente la protección ambiental, y que constituye un instrumento de incentivo al cumplimiento. De esta manera, queda establecido que se trata de un instrumento propio de la potestad sancionadora del Estado, reduciendo así las posibilidades de uso indebido del mismo, como por ejemplo, si quisiera otorgársele al PDC una vocación de instrumento económico más que de un instrumento de política sancionatoria.

A su vez, es relevante también explicitar la facultad de la SMA de rechazar un PDC, por razones de política sancionatoria. Ello por cuanto, dentro de una estrategia sancionatoria, en determinados casos se promueve de mejor manera el cumplimiento ambiental y el carácter disuasivo inherente a ella, a través de una sanción más que con un PDC.

En cuanto a su inserción dentro del procedimiento sancionatorio, sin perjuicio que le confiere fuerza como instrumento, al mismo tiempo le impone restricciones que pueden revisarse. Por ejemplo, el plazo excesivamente breve para presentar PDC por parte del "sujeto-infractor". Esta característica de la regulación ha promovido la vía de observaciones por parte de la SMA para su complementación y mejora, generando con ello dificultades y exigencias de carga administrativa para la misma autoridad, como son por ejemplo, determinar cuántas observaciones corresponde hacer sin que se abuse de dicha modalidad y se distorsionen los objetivos de protección ambiental del instrumento. Al respecto, se debe considerar que el infractor que presenta un PDC no dispone de un derecho a que este sea aprobado, aun cuando existan observaciones de por medio, y es la propia autoridad la que debe velar y garantizar un límite a éstas, manteniendo siempre la facultad de rechazar sin realizar observaciones cuando no se cumplen los requisitos mínimos para su presentación. A su vez, debiera aplicársele un plazo fatal a la SMA para resolver la aprobación o rechazo, aplicando las reglas de la Ley $\mathrm{N}^{\circ}$ 19.880, de 2003, lo anterior para evitar dilaciones excesivas de la autoridad que finalmente contravienen la esencia del instrumento, esto es, obtener en un plazo acotado el cumplimiento ambiental.

Otros aspectos que podrían revisarse dicen relación con los impedimentos para presentar un PDC, actualmente establecidos de manera confusa por el artículo 42, y las circunstancias para que proceda su modificación. A su vez, se debiera evaluar la incorporación en la ley de los elementos esenciales de los 
criterios de aprobación de un PDC, fortaleciendo de esta manera la potestad sancionadora de la SMA evitando así que sea la potestad reglamentaria y la discrecionalidad de la autoridad, la encargada de fijarlos.

Por otro lado, se podría considerar la incorporación de reglas formales de negociación con los interesados directos y con otros interesados, ${ }^{80}$ en el caso que no estén presentes en el respectivo procedimiento sancionatorio. Ello permitiría propender a mejores decisiones y a cumplir objetivos de justicia ambiental restaurativa, en la línea de lo que ha sostenido Macrory en el derecho anglosajón.

Por último, en materia de PDC cabe referirse a un aspecto que ha sido controvertido y dice relación con la "autoincriminación" que implicaría presentar este instrumento a la SMA por el sujeto infractor. En este sentido, sería necesario que la regulación distinguiera claramente entre los efectos del rechazo de un PDC y los efectos del incumplimiento del mismo, una vez que ya ha sido aprobado. El criterio adoptado por el Segundo Tribunal Ambiental contenido en la sentencia Rol " $R$ " $N^{\circ} 75-2015$, sostiene que la presentación, aprobación o rechazo de un PDC, indistintamente, no implica autoincriminación o aceptación de responsabilidad. Sin embargo, consideramos necesario diferenciar estos dos casos ya que la situación en que se encuentra el sujeto infractor al incumplir un PDC es de mayor gravedad que en el caso de su simple rechazo por la autoridad, ya que implica incurrir en un quiebre tanto del espíritu colaborativo que subyace al instrumento como de la buena fe comprometida en él, lo que debiera generar consecuencias claramente establecidas en la ley y no simplemente -como hoy se establece ${ }^{81}$ - un mero reproche facultativo de aplicar hasta el doble de la sanción, la que a su vez está limitada solo a la aplicación de una multa. ${ }^{82}$

\footnotetext{
${ }^{80}$ Otros interesados podrían ser miembros de las comunidades afectadas por la infracción o incluso organizaciones que representen intereses difusos, como es el medio ambiente, en cuanto bien jurídico protegido. ,ico protegido. manera que igualurtereses difusos, como es la protecciidad mientras se evalen revisarse. econe manera que igual

${ }^{81}$ Artículo 42, inciso $5^{\circ}$, LOSMA.

82 Bermúdez Soto, Jorge, Fundamentos de Derecho Ambiental, Ediciones Universitarias de Valparaíso,

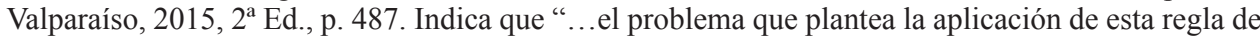
graduación de sanciones es si puede aplicarse respecto de otras sanciones distintas de la multa. La ley no entrega una respuesta y al tratarse de una disposición que claramente agrava la responsabilidad habrá que optar por una interpretación estricta de la misma. En la práctica la interrogante planteada será más bien aparente ya que la única posibilidad de aplicar este criterio de agravación de la sanción será en los casos de clausura temporal, en que podría plantearse una clausura por el doble de tiempo. Sin embargo, dado que la clausura temporal no está sujeta a límites máximos, la SMA podrá siempre utilizar como fundamento para una clausura muy extensa el criterio del literal i) del artículo 40,
} 
De esta manera, en caso de incumplimiento de un PDC, el procedimiento sancionatorio se debiera reiniciar solo para efectos de establecer el grado de ejecución del mismo con el fin de determinar la respuesta sancionatoria, en conformidad al artículo 40 de la LOSMA, no siendo necesario, por lo tanto acreditar, la configuración ni la clasificación de la infracción. Así también, se lograría un mayor incentivo al cumplimiento del instrumento por parte del sujeto infractor.

Respecto al resto de los instrumentos de incentivo al cumplimiento, mencionados al desarrollar este trabajo, ${ }^{83}$ cabe indicar algunas ideas que permitirían fortalecer su utilización estratégica por parte de la SMA. Por ejemplo, en relación con la autodenuncia -aún cuando no se analizó en detalle su regulación, sí vimos su escasa aplicación en la práctica- debe revisarse todo su diseño normativo para que este logre constituirse en un incentivo real y no meramente simbólico. Sin perjuicio que la SMA ha incorporado vía "Bases Metodológicas para la Determinación de Sanciones" mecanismos para ponderar positivamente su presentación, ${ }^{84}$ es necesario repensar el diseño regulatorio de los beneficios que conlleva. Por ejemplo, establecer un incentivo único y no escalonado, emulando al PDC, pero con regulación diferente en cuanto a oportunidad y requisitos de presentación, impedimentos y procedencia del beneficio.

Por su parte los planes de reparación deben ser igualmente revisados como instrumento de incentivo. Si bien, éste es de carácter indirecto, pues no incide en un beneficio en la sanción posible, sí lo es respecto a inhibir la acción por daño ambiental. A la fecha, como se indicó, no se ha presentado ningún plan de reparación, en los términos de la LOSMA ${ }^{85}$ habiendo existido casos donde era posible hacerlo. ${ }^{86} \mathrm{El}$ sancionado en estos casos ha

\footnotetext{
justificándolo en el incumplimiento del Programa de Cumplimiento”.

${ }^{83}$ Véase la sección II, parte 2, de este trabajo.

${ }^{84}$ Así, indica: “...en caso que el infractor presente una autodenuncia, pero no proceda la exención o rebaja señalada, ya sea porque la autodenuncia se declare inadmisible, o no se presente o apruebe el PDC respectivo, el hecho de haberse autodenunciado es considerado como un factor de disminución en la sanción...". V. SuPERINTENDENCIA DE Medio AmBIEnTE, Bases metodológicas para la determinación de sanciones ambientales. Actualización, cit. (n. 41).

85 Segundo Tribunal Ambiental, 22 de noviembre de 2018, "Estado de Chile en contra de la Sociedad Contractual Minera Compañía Minera Maricunga", Rol "D”-27-2016, disponible en www. tribunalambiental.cl. Mediante esta sentencia, el Tribunal ordena a Compañía Minera Maricunga a presentar a la SMA un plan de reparación ante la SMA, cuyo procedimiento de aprobación se deberá regir por las reglas del artículo 43 de la LOSMA.

${ }^{86}$ Superintendencia de Medio Ambiente (SMA), expediente sancionatorio Rol "D"-018-2015, "Minera Candelaria", disponible en http://snifa.sma.gob.cl/v2/Sancionatorio/Ficha/1220; Superintendencia de
} 
preferido reclamar la sanción o derechamente discutir el daño ambiental en el marco del procedimiento por demanda de reparación de daño ambiental, de conformidad lo dispone la Ley $\mathrm{N}^{\circ} 20.600$, de 2012 . Un buen camino para promover dicho instrumento podría consistir en que establecido el daño ambiental en sede sancionatoria administrativa, el Tribunal Ambiental lo deba reconocer, sin necesidad de volver a discutir su configuración en el marco de la acción por daño ambiental. ${ }^{87}$

Respecto a los demás instrumentos disponibles para el ejercicio de la potestad fiscalizadora y sancionatoria, cabe indicar que es necesario hacer cambios legales para que la SMA ejerza a plenitud y de manera comprensiva sus potestades. Desde ya, agregar las "cartas de advertencia" y la posibilidad de "corrección temprana" como mecanismos con fundamento legal expreso. Por otra parte, ampliar el alcance de algunos instrumentos más allá del ámbito del SEIA. ${ }^{88}$ En efecto, la LOSMA tiene un sesgo indiscutible, referido a que su normativa se aplica preferentemente respecto de las RCA. El esfuerzo por "deseisar" la institucionalidad ambiental no logra plasmarse plenamente en la LOSMA. Por ello, es fundamental que las atribuciones y mecanismos de intervención y control de la SMA comprendan toda la gama de instrumentos de carácter ambiental de los cuales es competente la SMA, reconociendo su diversidad y características propias. Por último, resulta fundamental para lograr una estrategia de fiscalización y sanción ambiental oportuna y efectiva, limitar el control preventivo ejercido por los Tribunales Ambientales, especialmente en la adopción de medidas como la detención de funcionamiento o clausura temporal, ello por cuanto limitan la celeridad y eficacia que exige el control del riesgo que está llamada a cautelar la SMA.

\footnotetext{
Medio Ambiente (SMA), expediente sancionatorio Rol "D"-014-2015, "Kinross - Refugio" (Minera Maricunga), disponible en http://snifa.sma.gob.cl/v2/Sancionatorio/Ficha/1215.

${ }^{87}$ Segundo Tribunal Ambiental, 8 de junio de 2016, "Pampa Camarones S.A. contra Superintendencia del Medio Ambiente", Rol "R"-51-2014, disponible en www.tribunalambiental.cl. La sentencia indica, en el considerando Septuagésimo octavo: "Que, de lo anterior, se colige que lo resuelto por el Tribunal al revisar la fundamentación de la SMA, en la aplicación del requisito contenido en el artículo 36 $\mathrm{N}^{\circ}$ 1, letra a) de la LOSMA, por tener un objetivo distinto, no implica necesariamente un antejuicio sobre la existencia de la responsabilidad por daño ambiental. En otras palabras, la configuración de este requisito para la clasificación de una infracción en el ámbito de la responsabilidad administrativa no trae aparejado una prueba anticipada del daño ambiental, en el ámbito de la responsabilidad civl, y viceversa, sin perjuicio que pueda ser considerado como un antecedente relevante para determinar su concurrencia".

${ }^{88}$ Por ejemplo, las Medidas Urgentes y Transitorias (MUT) sólo proceden respecto de “...las autorizaciones de funcionamiento contenidas en las Resoluciones de Calificación Ambiental" (artículo 3 letras g y h, LOSMA).
} 


\section{CONCLUSIONES}

A partir de lo expuesto en este trabajo, se puede concluir que existen una diversidad de instrumentos regulatorios disponibles para el ejercicio de las potestades de fiscalización, sanción y cumplimiento ambiental por parte de la SMA, sin perjuicio que adolecen de ciertas debilidades o insuficiencias que exigen un fortalecimiento regulatorio de los mismos. Por otra parte, todavía es necesaria la utilización de estos instrumentos con una mirada integral y estratégica institucional, de manera que el ejercicio de las potestades por parte de la autoridad sea consistente, eficaz y oportuno.

Se debe tener presente, sin embargo, que establecer la existencia, disponibilidad y utilización de estos instrumentos no implica necesariamente afirmar su eficacia en el cumplimiento ambiental. En efecto, en el caso del PDC, siendo el instrumento de incentivo al cumplimiento de mayor aplicación, no necesariamente significa que éste sea el instrumento más eficaz. Solo una vez que se disponga de un análisis comprensivo, respecto de un período razonable de tiempo, acerca de la ejecución del mismo, se podrá determinar si el PDC es un instrumento eficaz como instrumento de incentivo al cumplimiento. Lo mismo se puede sostener respecto de los demás instrumentos, tales como, por ejemplo, las cartas de advertencia respecto de las cuales ya se indicó que requieren de un seguimiento o trazabilidad para evaluar su real efecto como mecanismo de corrección al incumplimiento.

Por otro lado, es menester resaltar la necesidad que, con la experiencia lograda a la fecha y con la batería de instrumentos que dispone, la SMA elabore una estrategia integral de respuesta fiscalizadora y sancionadora, con todos los instrumentos considerados, permitiendo así que se adopten decisiones en el contexto de una política responsiva racional, eficiente y efectiva. Los instrumentos actuales identificados permiten proponer una escala responsiva a aplicar por parte de la SMA, de acuerdo a los riesgos o afectaciones involucrados y, al comportamiento del regulado, adoptando decisiones en etapa temprana -fiscalización- o, en una etapa más intensa -post fiscalización-, de tal manera de lograr respuestas más directas y eficaces. 
Dicha escala decisional de la respuesta ante el incumplimiento ambiental puede ser representada de la siguiente manera:

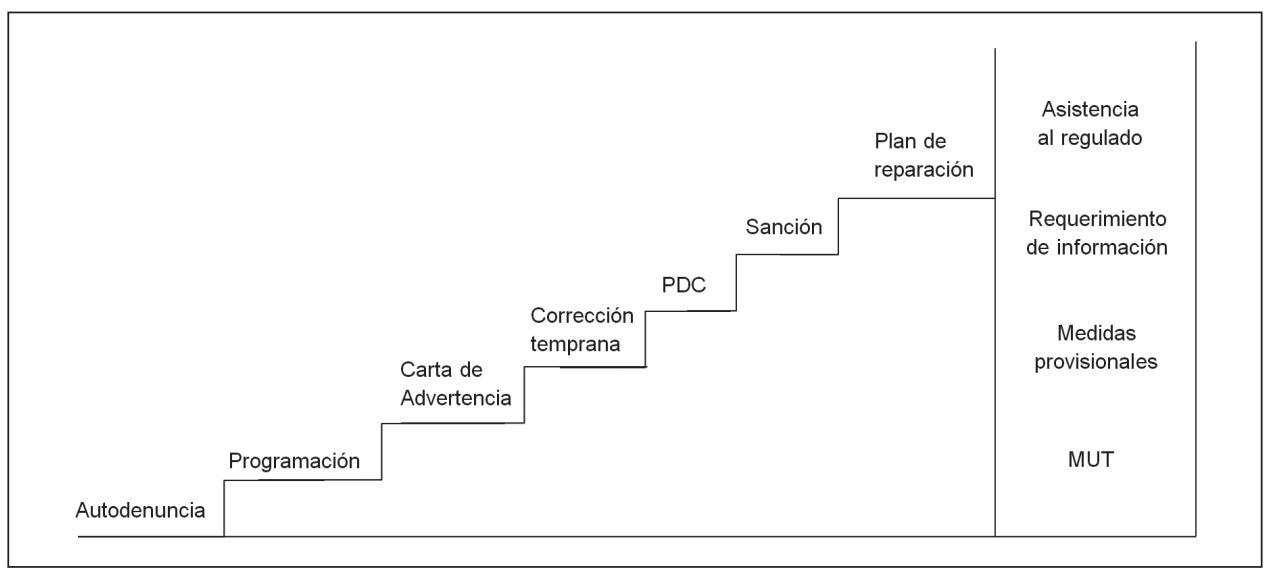

\section{BIBLIOGRAFIA}

\section{A) Doctrina}

Ayres, Ian; Braithwaite, John, Responsive Regulation. Transcending the Deregulation Debate, Oxford University Press, Oxford, 1992.

Bermudez Soto, Jorge, Fundamentos de Derecho Ambiental, Ediciones Universitarias de Valparaíso, Valparaíso, 2015, $2^{\mathrm{a}} \mathrm{Ed}$.

Gunningham, Neil, "Enforcing Environmental Regulation", Journal of Environmental Law, 2011, Vol. 23, N², pp. 169-201.

Holder, Jane; Lee, Maria, Environmental Protection, Law \& Policy, Cambridge University Press, Cambridge, 2007, 2 ${ }^{\text {a }}$ Ed.

MAcrory, Richard, Regulation, Enforcement and Governance in Environmental Law, Hart Publishing, Oxford \& Portland, Oregon, 2014, 2a Ed.

Ossandón Rosales, Jorge, Incentivos al Cumplimiento Ambiental, Editorial Libromar, Santiago, 2015.

Pedersen, Ole, "Environmental Enforcement Undertakings and Possible Implications: Responsive, Smarter or Rent Seeking?", The Modern Law Review 2013, 76 (2), pp. 319-345.

Plumer, Marie Claude; EspinozA, Ariel; Murh, Benjamín, "El Programa de Cumplimiento: Desarrollo actual e importancia del instrumento para la solución de conflictos ambientales", Revista de Derecho Ambiental, 2018, año VI, N9 (EneJun), pp. 209-236. 
Soто, Pablo, "Sanciones administrativas como medidas de cumplimiento del Derecho: un enfoque funcional y responsivo aplicado al régimen sancionatorio ambiental", Ius et Praxis, 2016, Año 22, N², pp. 189-226.

Superintendencia de Medio Ambiente (eds.), Bases metodológicas para la determinación de sanciones ambientales. Actualización, aprobada por Res. Exenta $N^{o}$ 85, de 22 de enero de 2018, Gobierno de Chile - SMA, Santiago, 2017 (pero 2018), 104 pp., disponible en línea: http://portal.sma.gob.cl/index.php/download/ bases-metodologicas-para-la-determinacion-de-sanciones-ambientales-2017/?wp $\mathrm{dmdl}=14238 \&$ masterkey $=5$ be 1 ea5f3eac 3 .

Superintendencia de Medio Ambiente (eds.), Guía para la presentación de autodenuncias por infracciones a instrumentos de carácter ambiental, Gobierno de Chile - SMA, Santiago, 2018, 22 pp., disponible en línea: https://portal.sma. gob.cl/index.php/portal-regulados/instructivos-y-guias/autodenuncias/.

Superintendencia de Medio Ambiente (eds.), Guía para la presentación de Programas de Cumplimiento por infracciones a instrumentos de carácter ambiental, Gobierno de Chile - SMA, Santiago, 2018, 56 pp., disponible en línea: https://portal.sma.gob.cl/index.php/download/guia-para-la-presentacion-deprogramas-de-cumplimiento-2/?wpdmdl=14300\&masterkey=5be3278b9af8 1

Winders, Delcianna, "Administrative Law Enforcement, Warnings and Transparency”, Ohio State Law Journal, 2018, Vol. 79:3, pp. 451-499.

ZINN, Matthew, "Policing Environmental Regulatory Enforcement: Cooperation, Capture and Citizen Suits", Stanford Environmental Law Journal, 2002, Vol. 21, pp. 81-174.

\section{B) Normativa}

Ley 20.417, Ley Orgánica Constitucional de la Superintendencia de Medio Ambiente (D. Of. 26 de enero de 2010).

Ley de Acuerdos de Producción Limpia: Artículo Décimo de la Ley $N^{\circ}$ 20.416, de 2010, Fija Normas Especiales para las Empresas de Menor Tamaño (D. Of. 3.02.2010).

Decreto Supremo $N^{\circ} 30$ de 2012, del Ministerio del Medio Ambiente, Reglamento sobre Programas de Cumplimiento, Autodenuncia y Planes de Reparación (D. Of. 11.02.2013).

Decreto Supremo N90, del 2000, del Ministerio Secretaría General de la Presidencia, establece norma de emisión para la regulación de contaminantes asociados a las descargas de residuos líquidos a aguas marinas y continentales superficiales (D. Of. 7.03.2001)

Resolución Exenta $\mathrm{N}^{\circ} 1184$ de 2015 de la Superintendencia de Medio Ambiente, de fecha 14 de diciembre de 2015. 


\section{C) Jurisprudencia}

Corte Suprema, 3 de julio de 2017, Rol Nº7.418-2016; disponible en www. pjud.cl.

Corte Suprema, 17 de julio de 2017, Rol N 58.986-2016; disponible en www.pjud.cl.

Corte Suprema, 6 de noviembre de 2017, Rol 36.202-2017; disponible en www.pjud.cl.

Corte Suprema, 5 de marzo de 2018, Rol N¹1.485-2017; disponible en www.pjud.cl.

Corte Suprema, 22 de mayo de 2018, Rol N 8456-2017, disponible en www.pjud.cl.

Corte Suprema, 29 de agosto de 2018, Rol № 3572-2018; disponible en www.pjud.cl.

Corte Suprema, 30 de octubre de 2018, Rol 16.328-2018, disponible en www.pjud.cl.

Primer Tribunal Ambiental, 6 de junio de 2018, "Interchile S.A. con Superintendencia del Medio Ambiente", Rol "R"-4-2018, disponible en https:// www. 1 ta.cl/

Segundo Tribunal Ambiental, 8 de junio de 2016, "Pampa Camarones S.A. contra Superintendencia del Medio Ambiente", Rol "R"-51-2014, disponible en www.tribunalambiental.cl.

Segundo Tribunal Ambiental, 22 de julio 2016, "Sociedad Vinícola Miguel Torres S.A. con Superintendencia del Medio Ambiente", Rol "R"-68-2015, disponible en www.tribunalambiental.cl.

Segundo Tribunal Ambiental, 2 de febrero de 2017, "Ecomaule S.A. con Superintendencia del Medio Ambiente", Rol "R"-112-2016, disponible en www. tribunalambiental.cl.

Segundo Tribunal Ambiental, 24 de febrero de 2017, "Pastene Solis con Superintendente del Medio Ambiente", Rol "R"-104-2016, disponible en www. tribunalambiental.cl.

Segundo Tribunal Ambiental, 28 de junio de 2017, “Carrasco Martínez con Superintendencia del Medio Ambiente", Rol "R"-116-2016, disponible en www. tribunalambiental.cl.

Segundo TribunalAmbiental, 29 de septiembre de2017, "SociedadContractual Minera Corporación de Desarrollo del Norte contra la Superintendencia del Medio Ambiente", causa Rol "R"- 82-2015, disponible en www.tribunalambiental.cl.

Segundo Tribunal Ambiental, 20 de octubre de 2017, "Leon Cabrera con Superintendencia del Medio Ambiente", Rol "R"-132-2016, disponible en www. tribunalambiental.cl.

Segundo Tribunal Ambiental, 30 de diciembre de 2017, “Compañía Minera 
Nevada SpA con Superintendencia del Medio Ambiente", Rol "R"-75-2015, disponible en www.tribunalambiental.cl.

Segundo Tribunal Ambiental, 29 de junio de 2018, "López Aránguiz con Superintendencia del Medio Ambiente", Rol "R"-163-2017, disponible en www. tribunalambiental.cl.

Segundo Tribunal Ambiental, 21 de agosto de 2018, "Sociedad Química y Minera de Chile S.A. con Superintendencia del Medio Ambiente", Rol "R"-1602017, disponible en www.tribunalambiental.cl.

Segundo Tribunal Ambiental, 14 de septiembre de 2018, "Velozo Rencoret, Hugo Rafael y otros contra Superintendencia del Medio Ambiente", causa Rol "R"- 153-2017, disponible en www.tribunalambiental.cl.

Segundo Tribunal Ambiental, 22 de noviembre de 2018, "Estado de Chile en contra de la Sociedad Contractual Minera Compañía Minera Maricunga", Rol "D"-27-2016, disponible en www.tribunalambiental.cl.

Tercer Tribunal Ambiental, 19 de agosto de 2016, "Barria Oyarzo con Superintendencia del Medio Ambiente", Rol "R"-36-2016, disponible en https:// causas.3ta.cl/

Tercer Tribunal Ambiental, 28 de noviembre de 2016, "Corporación Puelo Patagonia con Superintendencia del Medio Ambiente", Rol "R"-28-2016, disponible en https://causas.3ta.cl/

Tercer Tribunal Ambiental, 2 de febrero de 2018, "Stipicic Escauriaza con Superintendencia del Medio Ambiente", Rol "R"-58-2017, disponible en https:// causas.3ta.cl/

\section{D) Tramitación administrative}

Superintendencia de Medio Ambiente (SMA), expediente sancionatorio Rol D-001-2017, “AES Gener S.A.” (Alto Maipo), disponible en: http://snifa.sma.gob. $\mathrm{cl} / \mathrm{v} 2 /$ Sancionatorio/Ficha/1498.

Superintendencia de Medio Ambiente (SMA), expediente sancionatorio Rol D-013-2017, "Hidronor Chile S.A." (Pudahuel), disponible en: http://snifa.sma. gob.cl/v2/Sancionatorio/Ficha/1517.

Superintendencia de Medio Ambiente (SMA), expediente sancionatorio Rol F-049-2016, "Relleno Cerro La Leona", disponible en: http://snifa.sma.gob.cl/v2/ Sancionatorio/Ficha/1481.

Superintendencia de Medio Ambiente (SMA), expediente sancionatorio Rol D-064-2016, "Minera Los Pelambres", disponible en: http://snifa.sma.gob.cl/v2/ Sancionatorio/Ficha/1438.

Superintendencia de Medio Ambiente (SMA), expediente sancionatorio Rol D-043-2017, "Empresa de Transportes METRO S.A.”, disponible en: http://snifa. 
sma.gob.cl/v2/Sancionatorio/Ficha/1569.

Superintendencia de Medio Ambiente (SMA), expediente sancionatorio Rol D-067-2017, "Fuerte Corral 2", disponible en: http://snifa.sma.gob.cl/v2/ Sancionatorio/Ficha/1608.

Superintendencia de Medio Ambiente (SMA), expediente sancionatorio Rol F-059-2015, "Viña Morandé - Malloa” disponible en: http://snifa.sma.gob.cl/v2/ Sancionatorio/Ficha/1331.

Superintendencia de Medio Ambiente (SMA), expediente sancionatorio Rol F-029-2016, "Carozzi Planta Teno", disponible en http://snifa.sma.gob.cl/v2/ Sancionatorio/Ficha/1421.

Superintendencia de Medio Ambiente (SMA), expediente sancionatorio Rol F-048-2017, "Riles Viña Echeverría", disponible en: http://snifa.sma.gob.cl/v2/ Sancionatorio/Ficha/1630.

Superintendencia de Medio Ambiente (SMA), expediente sancionatorio Rol D-029-2018, "Levaduras Collico”, disponible en: http://snifa.sma.gob.cl/v2/ Sancionatorio/Ficha/1702.

Superintendencia de Medio Ambiente (SMA), expediente sancionatorio Rol D-046-2017, “Alifrut San Fernando", disponible en http://snifa.sma.gob.cl/v2/ Sancionatorio/Ficha/1576.

Superintendencia de Medio Ambiente (SMA), expediente sancionatorio Rol D-070-2017, "Viña Urcelay", disponible en http://snifa.sma.gob.cl/v2/ Sancionatorio/Ficha/1615.

Superintendencia de Medio Ambiente (SMA), expediente sancionatorio Rol "D"-018-2015, "Minera Candelaria", disponible en http://snifa.sma.gob.cl/v2/ Sancionatorio/Ficha/1220.

Superintendencia de Medio Ambiente (SMA), expediente sancionatorio Rol "D”-014-2015, "Kinross - Refugio" (Minera Maricunga), disponible en http:// snifa.sma.gob.cl/v2/Sancionatorio/Ficha/1215.

\section{E) Otros}

AvilÉs, Sebastián, "Promoción del cumplimiento en materia ambiental", columna, Diario La Tercera, 22.11.2018, disponible en línea: https:/www.latercera. $\mathrm{com} / \mathrm{pulso} /$ noticia/promocion-del-cumplimiento-materia-ambiental/412327/.

Noticia: "SMA presenta su Cuenta Pública 2017”, 28 de marzo de 2017, disponible en la página web del SMA, en línea: https://portal.sma.gob.cl/index. php/2018/04/25/sma-presenta-su-cuenta-publica-2017v2/ (visitada al 11.03.2019). 